University of Nebraska - Lincoln

DigitalCommons@University of Nebraska - Lincoln

3-2009

\title{
One-Pot Formation of Large Macrocycles with Modifiable Peripheries and Internal Cavities
}

Joseph S. Ferguson

State University of New York at Buffalo

Kazuhiro Yamato

State University of New York at Buffalo

Rui Liu

Beijing Normal University

Lan $\mathrm{He}$

Beijing Normal University, helan1961@yahoo.com.cn

Xiao Cheng Zeng

University of Nebraska-Lincoln, xzeng1@unl.edu

See next page for additional authors

Follow this and additional works at: https://digitalcommons.unl.edu/chemzeng

Part of the Chemistry Commons

Ferguson, Joseph S.; Yamato, Kazuhiro; Liu, Rui; He, Lan; Zeng, Xiao Cheng; and Gong, Bing, "One-Pot Formation of Large Macrocycles with Modifiable Peripheries and Internal Cavities" (2009). Xiao Cheng Zeng Publications. 102.

https://digitalcommons.unl.edu/chemzeng/102

This Article is brought to you for free and open access by the Published Research - Department of Chemistry at DigitalCommons@University of Nebraska - Lincoln. It has been accepted for inclusion in Xiao Cheng Zeng Publications by an authorized administrator of DigitalCommons@University of Nebraska - Lincoln. 


\section{Authors}

Joseph S. Ferguson, Kazuhiro Yamato, Rui Liu, Lan He, Xiao Cheng Zeng, and Bing Gong 
Published in Angewandte Chemie 121:17 (March 25, 2009), pp. 3196-3200; doi: 10.1002/ange.200900584 Copyright (C) 2009 WILEY-VCH Verlag $\mathrm{GmbH} \& \mathrm{Co}$. KGaA, Weinheim. Used by permission. http://www.angewandte.de

This work was supported by the US National Science Foundation (CHE-0701540), the Changjiang Scholar Program and the Cultivation Fund of the Key Scientific and Technical Innovation Project, Ministry of Education of China (grant 706009), the NSFC (grant 20672015 and 20772012 ), RFDP (grant 20070027038), Beijing NSFC (grant 2073024), Beijing Municipal Commission of Education, and Beijing New Medical Discipline Based Group (XK100270569).

Submitted January 31, 2009; published online March 25, 2009.

\title{
One-Pot Formation of Large Macrocycles with Modifiable Peripheries and Internal Cavities
}

\author{
Joseph S. Ferguson, ${ }^{1}$, Kazuhiro Yamato,${ }^{1}$, Rui Liu, ${ }^{2}$ Lan He, ${ }^{2}$ Xiao Cheng Zeng, ${ }^{3}$ and Bing Gong ${ }^{1,2}$ \\ ${ }^{1}$ Department of Chemistry, University at Buffalo, The State University of New York, Buffalo, NY 14260 (USA) \\ ${ }^{2}$ Colleges of Chemistry and Resources Science and Technology, and State Key Laboratory of Earth Surface Processes and Re- \\ source Ecology, Beijing Normal University, Beijing 100875 (China) \\ ${ }^{3}$ Department of Chemistry, University of Nebraska-Lincoln, Lincoln, NE 68588 (USA)
}

Corresponding authors — Lan He, helan1961@yahoo.com.cn ; Xiao Cheng Zeng Zeng@phase2.unl.edu ; Bing Gong bgong@chem.buffalo.edu

Macrocycles with persistent shape and large, noncollapsible lumens have attracted increasing interest because of their unique properties and potential applications. ${ }^{[1]}$ Although most of the macrocycles with well-defined shape have hydrocarbon backbones formed from the stepwise coupling of $\mathrm{sp}$ - or $\mathrm{sp}^{2}$-hybridized carbon atoms, ${ }^{[1 \mathrm{a}, \mathrm{b}, \mathrm{d}, 2]}$ macrocycles with other rigid backbones have also been reported. ${ }^{[3]}$ For example, we discovered a series of aromatic oligoamide macrocycles that could be generated in high yield by a one-pot macrocyclization process. ${ }^{[4]}$ These readily available macrocycles contain hydrophilic cavities that are rich in carbonyl oxygen atoms. With their persistent shape and noncollapsible cavities, these macrocycles have demonstrated unique features such as binding large cations with high affinity and specificity, ${ }^{[5]}$ and self-assembling into highly conducting transmembrane pores. ${ }^{[6]}$ The latest mechanistic study ${ }^{[4 \mathrm{~b}]}$ indicates that the folding of uncyclized oligoamide intermediates and precursors, which belong to a class of folding oligoamides with well-defined crescent conformations and tapelike backbones, ${ }^{[7]}$ plays a critical role in the observed high efficiency of the one-pot macrocyclization. The folding of the intermediates and precursors facilitates the one-pot cyclization, ${ }^{[8]}$ and at the same time impedes the formation of "overshooting" oligomers longer than the direct precursor of a macrocycle through remote steric hindrance. ${ }^{[4 b]}$ Herein we report that macrocycles with backbones other than aromatic oligoamides can also be formed with very high efficiency. Specifically, macrocycles with rigidified oligohydrazide backbones and nanosized cavities containing well-positioned, modifiable convergent sites can be obtained nearly exclusively in one step.

Similar to the crescent and helical oligoamides we had previously synthesized, the aromatic oligohydrazides consisting of meta-linked benzene rings are also known to fold into conformations with tapelike, hydrogen-bond-rigidified backbones. ${ }^{[9]}$ General structure 1 represents an unknown class of aromatic oligohydrazides consisting of meta-linked benzene and pyridine residues that should have a hydrogen-bond-enforced, curved backbone. The basic unit of $\mathbf{1}$ consists of a hy- drogen-bonded hydrazide group flanked by pyridyl $\mathrm{N}$ and ether $\mathrm{O}$ atoms that act as hydrogen-bond acceptors. The planar conformation of such a basic unit is illustrated by the optimized structure of hydrazide $\mathbf{1} \mathbf{a}^{\left[{ }^{10]}\right.}$ The structure of $\mathbf{1}$ a is rigidified by two highly favorable, three-center hydrogen bonds that are placed on either side of its hydrazide unit. These threecenter hydrogen bonds enforce $\mathbf{1}$ a to be planar. An oligomer consisting of such rigidified hydrazide units and meta-linked aromatic rings will be forced to fold into a crescent shape, which will allow cyclization to occur once it reaches a length that brings its two ends into proximity. Thus, oligomers based on 1 should have a folded, crescent-shaped backbone that may facilitate macrocyclization, thus leading to the corresponding macrocycle.
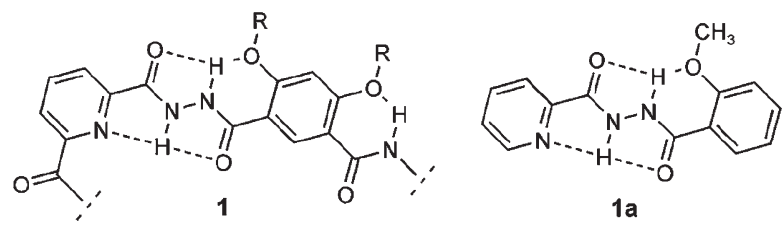

To test this possibility, acid chloride 2 (1 equiv) was treated with hydrazide 3 (1 equiv) in $\mathrm{CH}_{2} \mathrm{Cl}_{2}$ in the presence of 4-dimethylaminopyridine (DMAP) at $0{ }^{\circ} \mathrm{C}$ (Scheme 1$)$. The reaction mixture was allowed to warm to room temperature, and was then heated under reflux for $24 \mathrm{~h}$. The crude product was precipitated by adding diethyl ether. The MALDI mass spectrum of this product revealed a dominant signal $(m / z=1515.0)$ that corresponded to the $\left[\mathrm{M}+\mathrm{Na}^{+}\right]$ion of the six-residue macrocycle 4 . Purification by column chromatography gave pure 4 as a pale yellow solid in $73 \%$ yield. The ${ }^{1} \mathrm{H}$ and ${ }^{13} \mathrm{C}$ NMR spectra of 4 also revealed signals that are fully consistent with the symmetrical structure of this molecule. ${ }^{[10]}$ The highly efficient, nearly exclusive formation of $\mathbf{4}$ demonstrates that folding-assisted macrocyclization can indeed be extended to the preparation of macrocycles with a rigidified backbone besides that offered by aromatic oligoamides. 


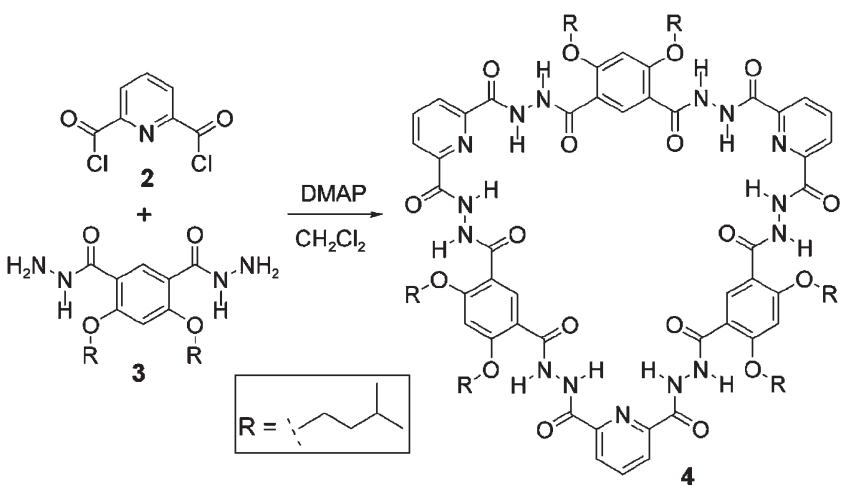

Scheme 1. One-pot formation of oligohydrazide macrocycle 4 consisting of meta-linked pyridine and benzene residues.

The six-residue 4 represents the first member of a new series of macrocycles. An exciting possibility offered by shapepersistent macrocycles involves the creation of modifiable internal cavities by placing well-positioned, multiple functionalities in a convergent fashion. Unfortunately, most currently known systems, ${ }^{[11]}$ including the oligoamide macrocycles we reported previously and macrocycle 4 described here, do not allow for easy modification of their internal cavities. Shapepersistent macrocycles with internal cavities of readily tunable size and properties could be formed in high yields by choosing a rigidified, curved backbone that allows the convergent placement of functional groups.

An oligohydrazide consisting of alternating meta- and paralinked benzene residues, as exemplified by general structure 5 (Figure 1 a), should have a hydrogen-bond-enforced, curved backbone with a convex edge and a concave edge. Macrocycles based on such a backbone should have both divergently $\left(R^{1}\right)$ and convergently $\left(R^{2}\right)$ placed side chains. The size and, more importantly, the function of the internal cavities can be tuned by adjusting the convergent groups. An additional feature provided by this design is that the presence of the paralinked residues leads to an overall reduced curvature of the backbone of 5, macrocycles based on which should have cavities of expanded sizes.

The structure of $\mathbf{5}$ is supported by the X-ray structure of $5 \mathrm{a}^{[9]}$ (Figure $\left.1 \mathrm{~b}\right)$, which adopts a completely planar conformation that is enforced by two sets of highly favorable, three-center hydrogen bonds. ${ }^{[12]}$ The reported noncyclic aromatic oligohydrazides were based on meta-linked benzene residues, and thus trimer $\mathbf{5} \mathbf{b}$ was examined by $2 \mathrm{D}$ (ROESY) ${ }^{1} \mathrm{H}$ NMR to provide insights into the folding of the meta/para-linked 5 . The

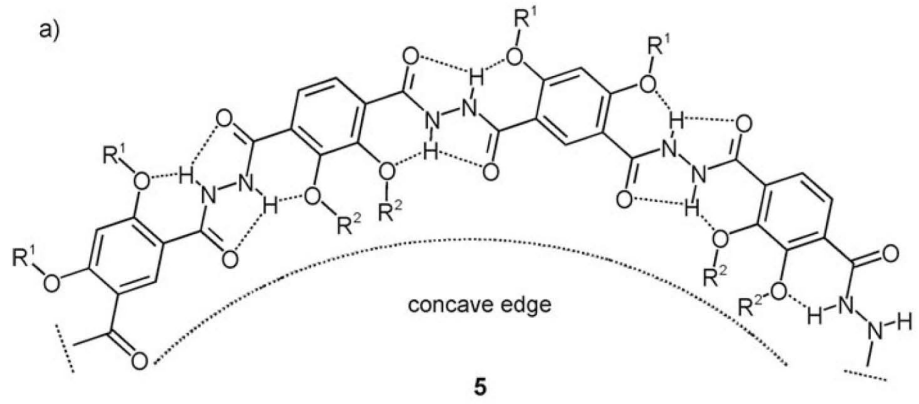

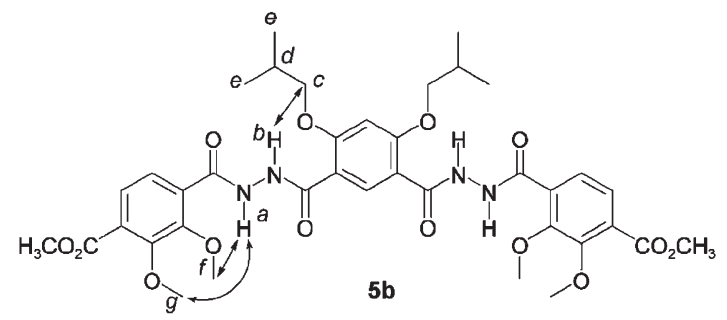

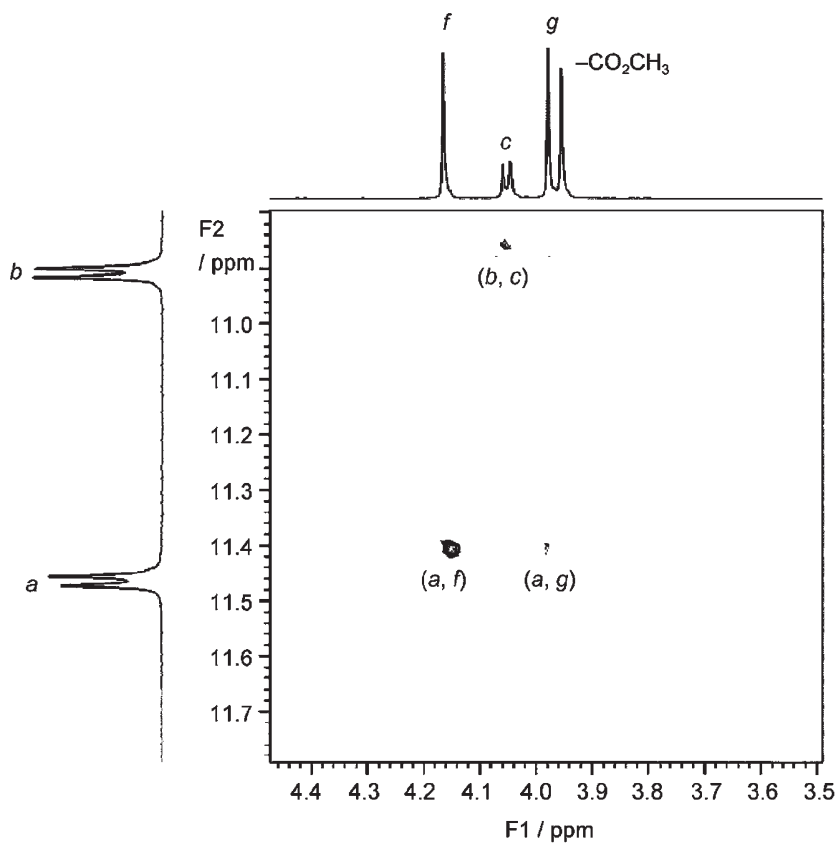

Figure 2. Partial ROESY ${ }^{1} \mathrm{H}$ NMR spectrum of trimer $\mathbf{5} \mathbf{b}$ recorded in $\mathrm{CDCl}_{3}(500 \mathrm{MHz}, 298 \mathrm{~K}$, mixing time=0.3 s)

ROESY spectrum of $\mathbf{5} \mathbf{b}$ recorded at room temperature (Figure 2) revealed significant ROE interactions between protons $a$ and $f, a$ and $g$, and $b$ and $c$, which suggests that $\mathbf{5} \mathbf{b}$ indeed adopts the expected crescent conformation that is enforced by intramolecular hydrogen bonds.

With the inclusion of para-linked residues, it was not clear whether the reaction between a diacid chloride and a dihydrazide (Scheme 2) would lead to the formation of cyclic product(s), linear oligomers, or both. Thus, acid chloride 6 a

Figure 1. a) The general structure shared by oligohydrazides containing alternating meta- and para-linked benzene residues connected by hydrogen-bond-rigidified hydrazide groups. Such an oligomer has a concave edge and a convex edge, to which convergently and divergently side chains are attached. b) The structure of $\mathbf{5}$ is supported by the known crystal structure of 5 a, which shows a completely planar conformation that is enforced by two sets of three-center hydrogen bonds. 
<smiles>[R]Oc1cc(O[R1])c(C([X])=O)cc1C([X])=O</smiles>

6 (1 equiv)

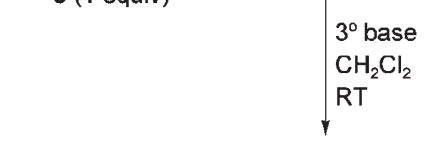<smiles>[R]Oc1cc(C(=O)NNC(=O)c2ccc(C(=O)NNC(=O)c3cc(C(N)=O)c(O[R])cc3O[R])c(O[R])c2O[R])c(O[R])cc1C(N)=O</smiles>

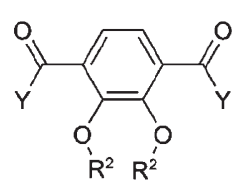

7 (1 equiv) 6a: $\mathrm{R}^{1}=s^{5} \mathrm{R}^{1}=s^{5} \mathrm{C} \mathrm{R}^{1}=s^{\mathrm{s}} \mathrm{Cl}$

7a: $\mathrm{R}^{2}=-\mathrm{Bn} ; \quad \mathrm{Y}=\mathrm{NHNH}_{2}$

7b: $\mathrm{R}^{2}=-\mathrm{CH}_{3} ; \mathrm{Y}=\mathrm{Cl}$

(1 equiv) was treated with hydrazide 7 a (1 equiv) in $\mathrm{CH}_{2} \mathrm{Cl}_{2}$ at room temperature. The crude product was obtained in $72 \%$ yield after removing the solvent, re-dissolving the solid residue in $\mathrm{CH}_{2} \mathrm{Cl}_{2}$, simple washing, and recrystallization from methanol. The crude product was analyzed by MALDI mass spectrometry, which revealed a dominant signal $(m / z=3564.9)$ that corresponded to the $\left[\mathrm{M}+\mathrm{Na}^{+}\right]$ion of the ten-residue macrocycle 8 a. Extensive purification by column chromatography (silica gel, chloroform/methanol) yielded 8 a in $54 \%$ yield.

The very high efficiency of this one-pot macrocyclization reaction was further demonstrated by treating acid chloride $6 \mathbf{b}$ with hydrazide 7 a under similar conditions. Examining the crude products from this reaction by MALDI mass spectrometry revealed that the corresponding macrocycle $\mathbf{8} \mathbf{b}(\mathrm{m} / \mathrm{z}=4144.2$, $\left.\left[M+\mathrm{Na}^{+}\right]\right)$existed as the dominant species. Washing a solution of the crude product in $\mathrm{CH}_{2} \mathrm{Cl}_{2}$ with aqueous $\mathrm{HCl}$ and $\mathrm{NaCl}$ afforded essentially pure (by ${ }^{1} \mathrm{H}$ NMR spectroscopy) macrocycle 8 b in $97 \%$ yield. ${ }^{[10]}$

In addition to the evidence provided by the MALDI mass spectra, the cyclic structures of macrocycles $\mathbf{8}$ a and $\mathbf{8} \mathbf{b}$ were clearly demonstrated by the simplicity of their ${ }^{1} \mathrm{H}$ NMR spectra. ${ }^{10]}$ The ${ }^{1} \mathrm{H}$ NMR signals corresponding to those of the hydrazide and aromatic protons (6.0-12.0 ppm) of each macrocycle can be unambiguously assigned to the two types of monomeric residues (Figure 3). Consistent with the symmetrical nature of their structures, the ${ }^{13} \mathrm{C}$ NMR spectra of these compounds also exhibit similar simplicity. ${ }^{[10]}$

Scheme 2. One-pot formation of oligohydrazide macrocycles 8 consisting of alternating meta- and para-linked benzene residues. $\mathrm{Bn}=$ benzyl.

a)

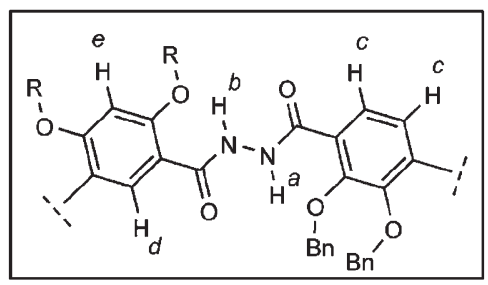

$5 a$

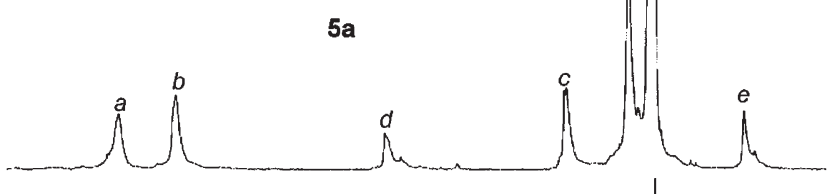

b)

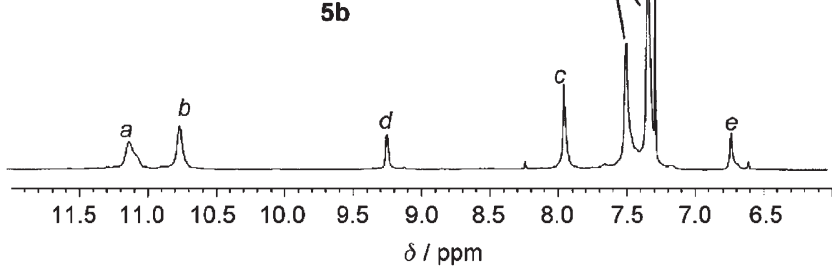

Figure 3 . The ${ }^{1} \mathrm{H}$ NMR spectra of a) $8 \mathrm{a}$ and b) $8 \mathrm{~b}$ recorded in $\mathrm{CDCl}_{3}(500 \mathrm{MHz})$.
The persistency of the three-center hydrogen bonds that rigidify the hydrazide groups and thus the backbone of $\mathbf{8} \mathbf{b}$ was demonstrated by intense NOE interactions between protons $a$ and $e, b$ and $c$, and $b$ and $d$ in its NOESY spectrum (Figure 4).

Compounds 6 and 7 can be readily prepared by procedures previously described, ${ }^{[13]}$ and allows the preparation of other ten-residue macrocycles that share the same backbone as $\mathbf{8} \mathbf{a}, \mathbf{b}$ but carry a wide variety of divergent $\left(R^{1}\right)$ and convergent $\left(\mathrm{R}^{2}\right)$ groups. The preparation of macrocycle $8 \mathrm{c}$ from diacid chloride $\mathbf{7} \mathbf{b}$ and hydrazide $6 \mathrm{c}$ (Scheme 2) demonstrated that neither $R^{1}$ nor $R^{2}$ had any effect on the efficiency of the one-pot condensation. Crude macrocycle $8 \mathrm{c}$ was obtained in $91 \%$ yield after washing the reaction mixture in $\mathrm{CH}_{2} \mathrm{Cl}_{2}$ with aqueous $\mathrm{HCl}$ and brine, and in $62 \%$ yield after purification by column chromatography. The cyclic structure of $\mathbf{8 c}$ was confirmed by the $\left[M+\mathrm{Na}^{+}\right]$signal $(m / z=2804.5)$ in its MALDI mass spectrum, along with the isotope distribution pattern of this signal. ${ }^{10]}$ However, attempts to characterize $8 \mathrm{c}$ by ${ }^{1} \mathrm{H}$ and ${ }^{13} \mathrm{C}$ NMR spectroscopy have so far resulted in spectra with either very poor resolution $\left({ }^{1} \mathrm{H} \mathrm{NMR}\right)$ or no signals $\left({ }^{13} \mathrm{C} \mathrm{NMR}\right)$, which was most likely a consequence of strong intermolecular aggregation of $\mathbf{8} \mathbf{c}$.

A unique feature offered by the general design of 8 is that the multiple convergent sites in the internal cavities of these macrocycles can be adjusted, either by incorporating monomers 


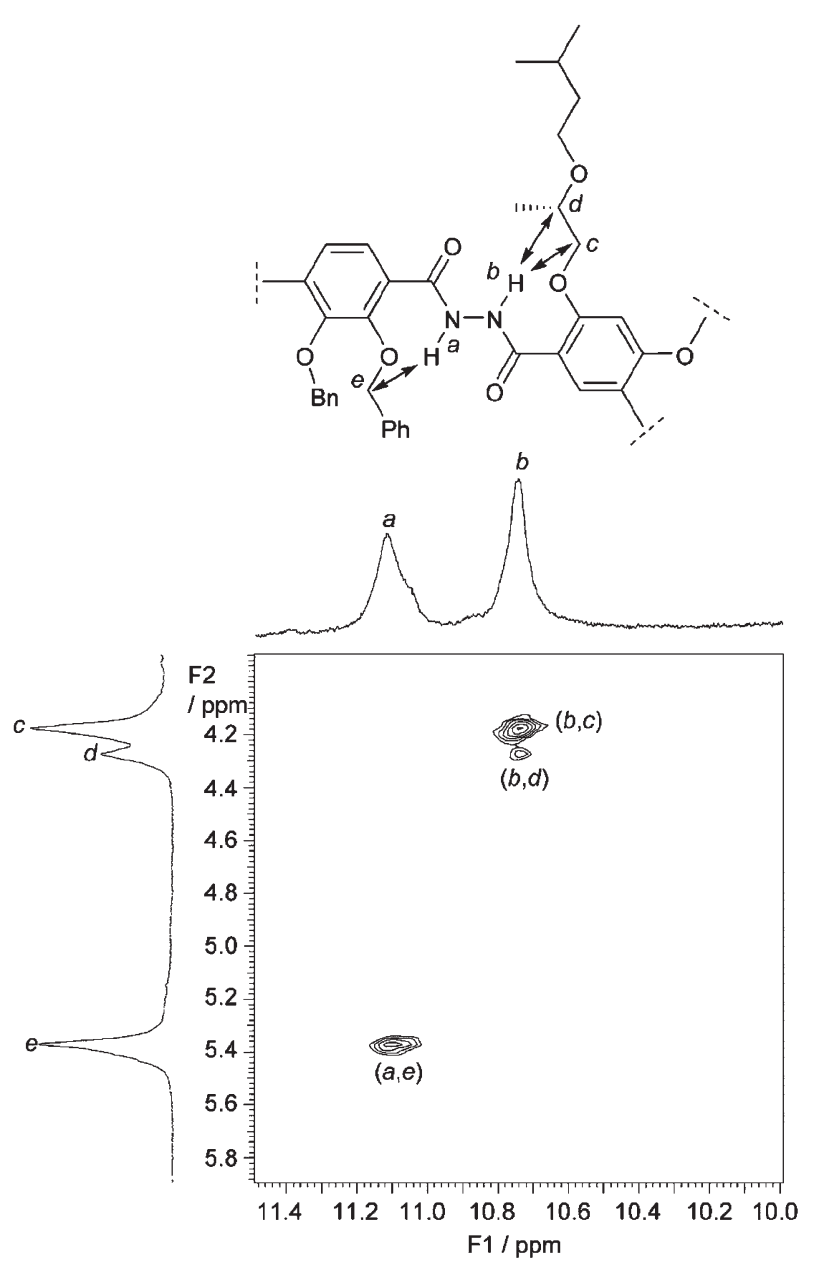

Figure 4. Partial 2D (NOESY) ${ }^{1} \mathrm{H}$ NMR spectrum of $8 \mathbf{b}$ recorded in $\mathrm{CDCl}_{3}(500 \mathrm{MHz}, 293 \mathrm{~K}$, mixing time=70 ms).

carrying the desired side chains or by performing a post-cyclization modification. For example, removing the benzyl groups of $\mathbf{8} \mathbf{a}$ and $\mathbf{8} \mathbf{b}$ should expose the hydroxy groups of the catechol moieties. Functional groups could then be introduced through ester, ether, acetal, or other linkages. Furthermore, the hydroxy groups of the catechol moieties should provide multiple sites for the binding of metal ions, thereby leading to cavities with catalytic capability.

The structures of macrocycles 4 and 8 ( $R$ replaced with methyl) were optimized by using an ab initio method at the B3LYP/6-31(g)d level of theory. [14] These macrocycles have flat backbones rigidified by three-center hydrogen bonds (Figure 5). The planar shape of both 4 and 8 reflects the high strength of the three-center hydrogen bonds, which enforces the hydrogen-bond donor and acceptors involved to be coplanar. Macrocycle 4 has a triangular shape, with an internal cavity of approximately $10 \AA$ diameter. Macrocycle $\mathbf{8}$ is much larger than 4 , with an overall round shape and an internal cavity that provides ten well-positioned, multiple convergent sites. In the optimized structure of $\mathbf{8}$, the ten convergent methyl groups project above and below the plane of the macrocyclic backbone, thus leading to a cavity with a diameter of about $21 \AA$.

In summary, the highly efficient, one-pot formation of new shape-persistent macrocycles having hydrogen-bond-ri-
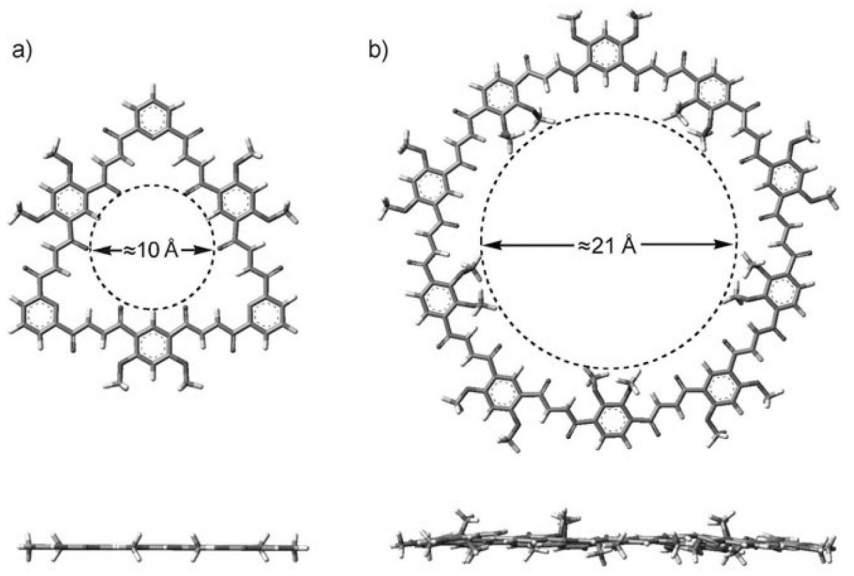

Figure 5. Top and side views of the structures of macrocycles a) 4, and b) 8 optimized at the B3LYP/6-31(g)d level. All side chains were replaced with methyl groups to save computational time.

gidified oligohydrazide backbones has been described. The one-pot reactions use readily available starting materials and should lead to large quantities of a variety of macrocycles. Adjusting the divergent side chains allows the peripheries, and thus the solubility, of the macrocycles to be tuned. With their flat backbones and large diameters, these macrocycles should undergo self-organization typical of disclike molecules, ${ }^{[15]}$ thereby leading to columnar aggregates containing nanosized channels. The efficient formation of 8 a-c has opened up a new approach to constructing shape-persistent macrocyles with internal cavities containing multiple convergent sites. Incorporating different functionalities into these convergent sites will lead to noncollapsible cavities with systematically tunable sizes and properties, which will enable hosts to be designed that are capable of targeting guests that are otherwise difficult to recognize. Despite the kinetic nature of the bond-forming reaction, the one-pot nearly exclusive formation of 4 and the much larger 8 , along with the previously reported one-pot generation of aromatic oligoamide macrocycles, ${ }^{[4]}$ rival those observed for macrocyclization reactions under thermodynamic conditions. ${ }^{[16]}$ Thus, these systems have established folding-assisted macrocyclization as a new, general method for the efficient synthesis of shape-persistent macrocycles from folded intermediates and precursors.

\section{References}

[1] a) C. Grave, A. D. Schlüter, Eur. J. Org. Chem. 2002, 3075; b) S. Höger, Chem. Eur. J. 2004, 10, 1320; c) Z. R. Laughrey, B. C. Gibb, Top. Curr. Chem. 2005, 249, 67; d) W. Zhang, J. S. Moore, Angew. Chem. 2006, 118, 4524; Angew. Chem. Int. Ed. 2006, 45, 4416; e) M. J. MacLachlan, Pure Appl. Chem. 2006, 78, 873.

[2] a) M. Mayor, C. Didschies, Angew. Chem. 2003, 115, 3284; Angew. Chem. Int. Ed. 2003, 42, 3176; b) K. Nakao, M. Nishimura, T. Tamachi, Y. Kuwatani, H. Miyasaka, T. Nishinaga, M. Iyoda, J. Am. Chem. Soc. 2006, 128, 16740.

[3] a) H. Jiang, J. M. Leger, P. Guionneau, I. Huc, Org. Lett. 2004, 6, 2985; b) L. Y. Xing, U. Ziener, T. C. Sutherland, L. A. Cuccia, Chem. Commun. 2005, 5751; c) C. Rotger, M. N. Pina, M. Vega, P. Ballester, P. M. Deya, A. Costa, 
Angew. Chem. 2006, 118, 6998; Angew. Chem. Int. Ed. 2006, 45, 6844; d) J. Sakamoto, A. D. Schlüter, Eur. J. Org. Chem. 2007, 2700; e) F. Campbell, J. Plante, C. Carruthers, M. J. Hardie, T. J. Prior, A. J. Wilson, Chem. Commun. 2007, 2240; f) J. M. Holub, H. J. Jang, K. Kirshenbaum, Org. Lett. 2007, 9, 3275;g) J. B. Lin, X. N. Xu, X. K. Jiang, Z. T. Li, J. Org. Chem. 2008, 73, 9403; h) I. Alfonso, M. Bolte, M. Bru, M. I. Burguete, S. V. Luis, J. Rubio, J. Am. Chem. Soc. 2008, 130, 6137; i) B. Qin, X. Y. Chen, X. Fang, Y. Y. Shu, Y. K. Yip, Y. Yan, S. Y. Pan, W. Q. Ong, C. L. Ren, H. B. Su, H. Q. Zeng, Org. Lett. 2008, 10, 5127.

[4] a) L. H. Yuan, W. Feng, K. Yamato, A. R. Sanford, D. G. Xu, H. Guo, B. Gong, J. Am. Chem. Soc. 2004, 126, 11120; b) W. Feng, K. Yamato, L. Q. Yang, J. S. Ferguson, L. J. Zhong, S. L. Zou, S. L. H. Yuan, X. C. Zeng, B. Gong, J. Am. Chem. Soc. 2009, 131, 2629; c) B. Gong, Acc. Chem. Res. 2008, 41, 1376.

[5] A. R. Sanford, L. H. Yuan, W. Feng, K. Yamato, R. A. Flowers, B. Gong, Chem. Commun. 2005, 4720.

[6] A. J. Helsel, A. L. Brown, K. Yamato, W. Feng, L. H. Yuan, A. J. Clements, S. V. Harding, G. Szabo, Z. F. Shao, B. Gong, J. Am. Chem. Soc. 2008, 130, 15784.

[7] a) J. Zhu, R. D. Parra, H. Q. Zeng, E. Skrzypczak-Jankun, X. C. Zeng, B. Gong, J. Am. Chem. Soc. 2000, 122, 4219; b) B. Gong, et al., Proc. Natl. Acad. Sci. USA 2002, 99, 11583; c) L. H. Yuan, H. Q. Zeng, K. Yamato, A. R. Sanford, W. Feng, H. S. Atreya, D. K. Sukumaran, T. Szyperski, B. Gong, J. Am. Chem. Soc. 2004, 126, 16528.

[8] For some examples of macrocyclizations promoted by conformational preorganization, see a) F. J. Carver, C. A. Hunter, R. J. Shannon, J. Chem. Soc. Chem. Commun. 1994, 1277; b) J. Blankenstein, J. Zhu, Eur. J. Org. Chem. 2005, 1949.
[9] J. L. Hou, X. B. Shao, G. J. Chen, Y. X. Zhou, X. K. Jiang, Z. T. Li, J. Am. Chem. Soc. 2004, 126, 12386.

[10] See the Supporting Information for details.

[11] For examples of macrocycles containing convergently arranged functionalities prepared by template-directed synthesis, see a) M. Fischer, G. Lieser, A. Rapp, I. Schnell, W. Mamdouh, S. De Feyter, F. C. De Schryver, S. Höger, J. Am. Chem. Soc. 2004, 126, 214; b) S. H. Jung, W. Pisula, A. Rouhanipour, H. J. Rader, J. Jacob, K. Mullen, Angew. Chem. 2006, 118, 4801; Angew. Chem. Int. Ed. 2006, 45,4685 ; c) for a recent example of compounds containing cages with convergent functional groups, see M. Mastalerz, Chem. Commun. 2008, 4756.

[12] R. D. Parra, H. Q. Zeng, J. Zhu, C. Zheng, X. C. Zeng, B. Gong, Chem. Eur. J. 2001, 7, 4352.

[13] L. H. Yuan, A. R. Sanford, W. Feng, A. M. Zhang, J. S. Ferguson, K. Yamato, J. Zhu, H. Q. Zeng, B. Gong, J. Org. Chem. 2005, 70, 10660.

[14] M. J. Frisch, et al. GAUSSIAN 03 (Gaussian, Pittsburg, 2004), Revision C. 02.

[15] S. Laschat, A. Baro, N. Steinke, F. Giesselmann, C. Hagele, G. Scalia, R. Judele, E. Kapatsina, S. Sauer, A. Schreivogel, M. Tosoni, Angew. Chem. 2007, 119, 4916; Angew. Chem. Int. Ed. 2007, 46, 4832.

[16] a) A. J. Gallant, M. J. MacLachlan, Angew. Chem. 2003, 115, 5465; Angew. Chem. Int. Ed. 2003, 42, 5307; b) A. J. Gallant, J. K.-H. Hui, F. E. Zahariev, Y. A. Wang, M. J. MacLachlan, J. Org. Chem. 2005, 70, 7936; c) W. Zhang, J. S. Moore, J. Am. Chem. Soc. 2006, 128, 11863; d) C. S. Hartley, J. S. Moore, J. Am. Chem. Soc. 2007, 129, 11682. 


\section{One-pot Formation of Large Macrocycles with Modifiable Peripheries and Internal Cavities}

Joseph S. Ferguson, Kazuhiro Yamato, Rui Liu, Lan He,* Xiao Cheng Zeng, * and Bing Gong*

Dr. J. Ferguson, Dr. K. Yamato, Prof. B. Gong

Department of Chemistry

University at Buffalo

The State University of New York

Buffalo, New York 14260 (USA)

Fax: (+1) 7166456963

E-mail:bgong@chem.buffalo.edu

Mr. R. Liu, Prof. L. He, Prof. B. Gong

Colleges of Chemistry and Resources Science and Technology, and State Key Laboratory of Earth Surface Processes and Resource Ecology

Beijing Normal University

Beijing 100875 (P. R. China)

E-mail: helan1961@yahoo.com.cn

Prof. X. C. Zeng

Department of Chemistry

University of Nebraska-Lincoln

Lincoln, Nebraska 68588 (USA)

E-mail: xczeng@phase2.unl.edu

\section{Supporting Information}




\section{Synthetic Procedures}

Scheme S1. Synthesis of trimer $\mathbf{5 b}$
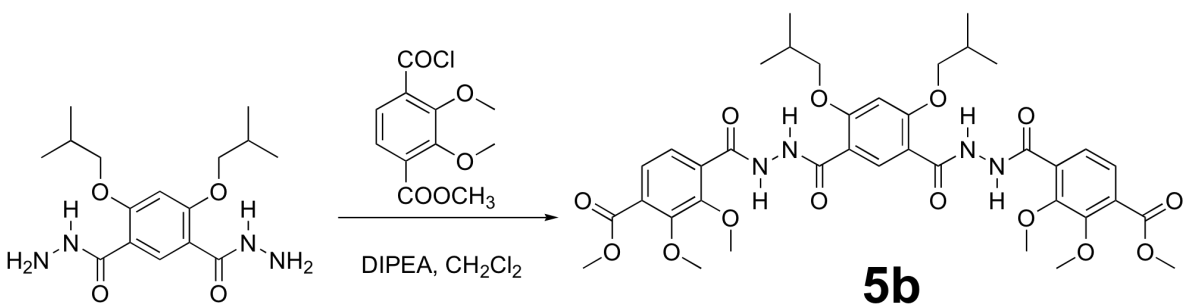

A solution of monoacid chloride $(6.4 \mathrm{mmol})$ was prepared by treating with thionyl chloride. The corresponding acid chloride was added drop wise to a solution of the dihydrazide (3.2 mmol), N,Ndiisopropylethylamine $(15.8 \mathrm{mmol})$, and methylene chloride $(40 \mathrm{~mL})$. After refluxing overnight, methanol $(30 \mathrm{~mL})$ was added to the reaction mixture. The solvent was evaporated under vacuum and the product was obtained as a white solid from recrystallization in methanol $(1.58 \mathrm{~g}, 64 \%) .{ }^{1} \mathrm{H}$ NMR $\left(500 \mathrm{MHz}, \mathrm{CDCl}_{3}\right) \delta 11.46(\mathrm{~d}, J=8.4 \mathrm{~Hz}, 2 \mathrm{H}), 10.91(\mathrm{~d}, J=8.1 \mathrm{~Hz}, 2 \mathrm{H}), 9.18(\mathrm{~s}, 1 \mathrm{H}), 7.96$ $(\mathrm{d}, J=8.4 \mathrm{~Hz}, 2 \mathrm{H}), 7.61(\mathrm{~d}, J=8.1 \mathrm{~Hz}, 2 \mathrm{H}), 6.58(\mathrm{~s}, 1 \mathrm{H}), 4.16(\mathrm{~s}, 6 \mathrm{H}), 4.05(\mathrm{~d}, J=6.5 \mathrm{~Hz}, 4 \mathrm{H})$, $3.98(\mathrm{~s}, 6 \mathrm{H}), 3.96(\mathrm{~s}, 6 \mathrm{H}), 2.58-2.48(\mathrm{~m}, 2 \mathrm{H}), 1.23(\mathrm{~d}, J=6.5 \mathrm{~Hz}, 12 \mathrm{H}) ;{ }^{13} \mathrm{C}$ NMR $(125.7 \mathrm{MHz}$, $\left.\mathrm{CDCl}_{3}\right) \delta 165.72,161.10,158.80,157.16,153.21,152.54,137.10,129.80,127.40,125.80,123.99$, 112.63, 99.41, 94.84, 77.34, 61.92, 52.48, 28.37, 19.57; MS (ESI) m/z, Calcd for $\mathrm{C}_{38} \mathrm{H}_{46} \mathrm{~N}_{4} \mathrm{O}_{14}(\mathrm{M})$ 782.30, Found 783.1 $\left(\mathrm{M}+\mathrm{H}^{+}\right), 805.2\left(\mathrm{M}+\mathrm{Na}^{+}\right)$.

Scheme S2. One-step formation of marcocyle 4.
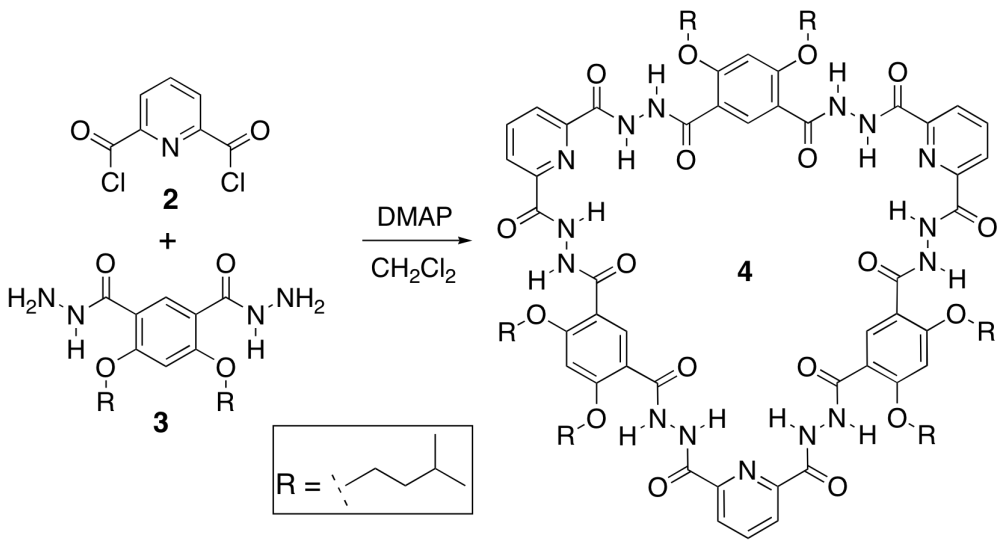

A solution of $2(1.2 \mathrm{mmol})$ in methylene chloride $(4 \mathrm{~mL})$ was added dropwise to a solution of $\mathbf{3 a}$ $(0.438 \mathrm{~g}, 1.2 \mathrm{mmol})$ in methylene $(26 \mathrm{~mL})$ at $0{ }^{\circ} \mathrm{C}$ for 2 hours in the presence of DMAP $(0.176 \mathrm{~g}$, $2.4 \mathrm{mmol})$. The reaction mixture was allowed to warm to room temperature, and was then heated under reflux for 24 hours. The mixture was washed with $8 \% \mathrm{HCl}$ and brine. To the organic layer was added diethyl ether $(30 \mathrm{~mL})$ and the precipitate formed was collected by filtration. The resultant crude product, a yellow solid, was purified by column chromatography using chloroform/methanol $(30 / 1,10 / 1)$ to give 4 as a light yellow solid $(0.434 \mathrm{~g}$, yield $73 \%)$. ${ }^{1} \mathrm{H}$ NMR (DMSO- $\left.d_{6}, 400 \mathrm{MHz}, 323 \mathrm{~K}\right) \delta 11.42(\mathrm{~s}, 6 \mathrm{H}), 9.93(\mathrm{~s}, 6 \mathrm{H}), 8.41(\mathrm{~s}, 3 \mathrm{H}), 8.30(\mathrm{~m}, 9 \mathrm{H}), 6.92(\mathrm{~s}, 3 \mathrm{H})$, $4.37(\mathrm{t}, J=6.4 \mathrm{~Hz}, 12 \mathrm{H}), 1.89(\mathrm{~m}, 12 \mathrm{H}), 1.81(\mathrm{~m}, 6 \mathrm{H}), 0.98(\mathrm{~d}, J=6.3 \mathrm{~Hz}, 36 \mathrm{H}) .{ }^{13} \mathrm{C}$ NMR (DMSO- $\left.d_{6}, 100 \mathrm{MHz}\right) \delta 164.26,162.16,160.85,148.27,140.35,134.56,125.67,114.21,98.52$, 68.38, 37.46, 25.04, 23.92. MS (MALDI-TOF) $\mathrm{m} / \mathrm{z}$, calcd for $\mathrm{C}_{75} \mathrm{H}_{93} \mathrm{~N}_{15} \mathrm{O}_{18} 1491.68\left(\mathrm{M}^{+}\right.$), found $1515.0\left(\mathrm{M}+\mathrm{Na}^{+}\right), 1531.0\left(\mathrm{M}+\mathrm{K}^{+}\right)$.

Scheme S3. One-step formation of macrocycles 8a-c. 


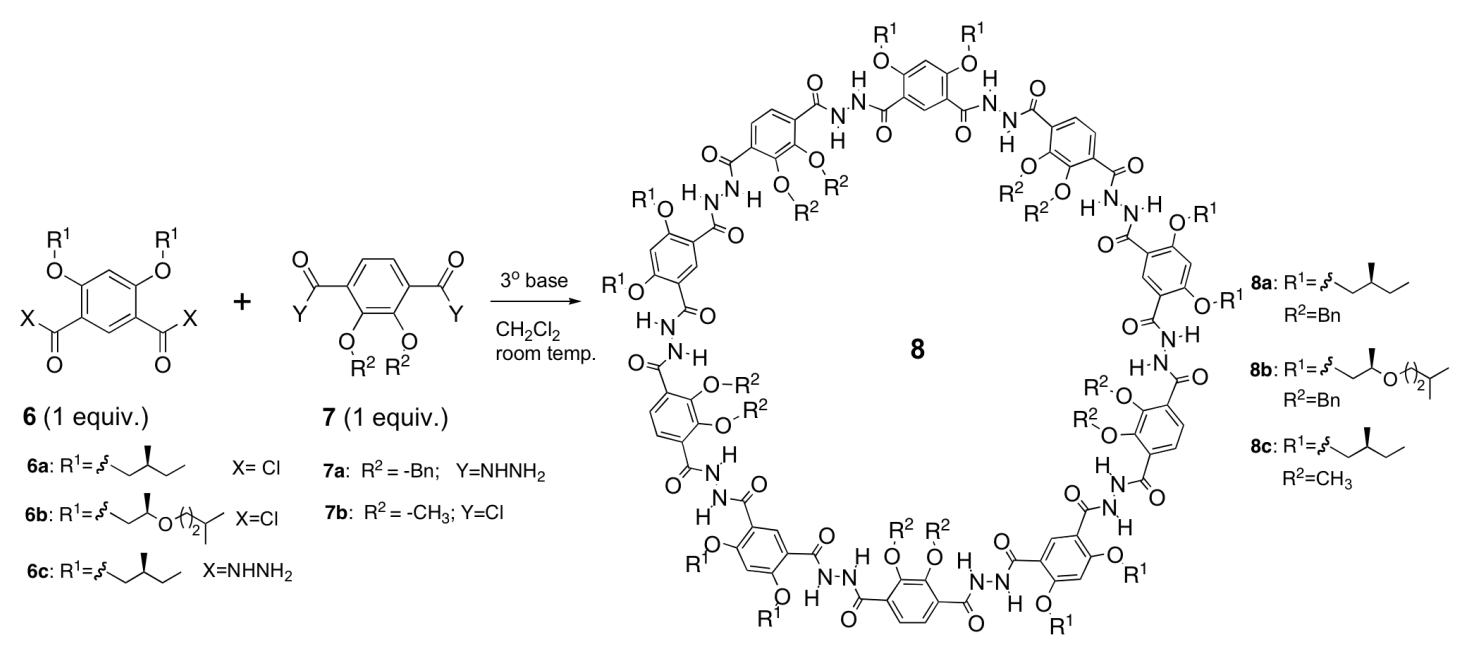

General procedure. A solution of dihydrazide (1 equiv.) and N,N-diisopropylethylamine (DIPEA) was prepared in dry methylene chloride under an Ar atmosphere. A solution of diacid chloride (1 equiv.) in methylene chloride was then added dropwise over a period of 10 minutes with stirring. Reaction was then allowed to continue at reflux overnight. Methanol was then added to quench any unreacted acid chloride. The mixture was concentrated under vacuum, and then redissolved in methylene chloride. The $\mathrm{CH}_{2} \mathrm{Cl}_{2}$ was washed with $10 \% \mathrm{HCl}$ and brine. The organic layer was dried over sodium sulfate and the solvent was removed under vacuum. The crude mixture was then purified using either recrystallization in methanol/chloroform or column chromatography (silica gel, chloroform/methanol, 10/1).

Macrocycle 8a: A solution of diacid chloride 6a $(2.44 \mathrm{mmol})$ in methylene chloride $(4 \mathrm{~mL})$ was added dropwise to a solution of dihydrazide $7 \mathbf{a}(2.44 \mathrm{mmol})$ in methylene chloride $(80 \mathrm{~mL})$ at room temperature for one hour in the presence of DIPEA $(12.2 \mathrm{mmol})$. The reaction mixture was heated under refluxed for 18 hours, at which point methanol $(50 \mathrm{~mL})$ was added. Solvent was evaporated off to yield a solid residue that was then redissolved into methylene chloride. The organic solution was washed with $10 \% \mathrm{HCl}$ and brine. The solution was dried over sodium sulfate and the solvent was evaporated under vacuum. The resulting solid was recrystallized in methanol to obtain the crude product $(1.24 \mathrm{~g}, 72 \%)$. The crude product was analyzed via MALDI-MS and confirmed to contain the cyclic $\mathbf{8 a}$ as the dominant product. The crude solid was purified using column chromatography (silica gel in chloroform/methanol, 10:1) to yield cyclic 10mer 8a $(0.934 \mathrm{~g}, 54 \%)$. ${ }^{1} \mathrm{H}$ NMR $\left(400 \mathrm{MHz}, \mathrm{CDCl}_{3}\right) \delta 11.18(\mathrm{~s}, 10 \mathrm{H}), 10.77$ (s, 10H), 9.24, (s, 5H), $7.93(\mathrm{~s}, 10 \mathrm{H}), 7.46-7.31$ $(\mathrm{m}, 50 \mathrm{H}), 6.60(\mathrm{~s}, 5 \mathrm{H}), 5.37(\mathrm{~s}, 20 \mathrm{H}), 4.16-4.06(\mathrm{~m}, 20 \mathrm{H}), 2.27(\mathrm{~m}, 10 \mathrm{H}) 1.70(\mathrm{~m}, 10 \mathrm{H}), 1.46(\mathrm{~m}$, 10H), 1.21 (d, 30H), 1.06 (d, $30 \mathrm{H}) ;{ }^{13} \mathrm{C}$ NMR (75 MHz, CDCl3) §161.09, 158.65, 158.05, 149.96, $137.19,136.52,134.54,129.91,129.18,129.06,128.95,128.87,128.63,128.51,126.17,112.63$, 96.31, 75.19, 34.51, 26.34, 16.96, 11.19. MS (MALDI-TOF) m/z, Calcd for $\mathrm{C}_{200} \mathrm{H}_{220} \mathrm{~N}_{20} \mathrm{O}_{40} 3541.6$ $\left(\mathrm{M}^{+}\right)$, Found $3564.9\left(\mathrm{M}+\mathrm{Na}^{+}\right)$.

Macrocycle 8b: A solution of diacid chloride $6 \mathbf{b}(0.253 \mathrm{mmol})$ in methylene chloride $(1 \mathrm{~mL})$ was added dropwise to a solution of dihydrazide $7 \mathbf{a}(0.253 \mathrm{mmol})$ in methylene chloride $(20 \mathrm{~mL})$ at room temperature in the presence of $\mathrm{N}, \mathrm{N}$-Diisopropylethylamine $(1.27 \mathrm{mmol})$. The reaction mixture was stirred and refluxed for 18 hours, at which point methanol $(50 \mathrm{~mL})$ was added. Solvent was evaporated off and the mixture was redissolved in methylene chloride. The organic layer was washed with $10 \% \mathrm{HCl}$, followed by $10 \% \mathrm{NaCl}$, and then dried over sodium sulfate. The solvent was evaporated under vacuum to yield macrocycle $\mathbf{8 b}$ as a yellow solid $(0.204 \mathrm{~g}, 97 \%)$. ${ }^{1} \mathrm{H}$ NMR $\left(500 \mathrm{MHz}, \mathrm{CDCl}_{3}\right) \delta 11.11(\mathrm{~s}, 10 \mathrm{H}), 10.74(\mathrm{~s}, 10 \mathrm{H}), 9.23,(\mathrm{~s}, 5 \mathrm{H}), 7.93(\mathrm{~s}, 10 \mathrm{H}), 7.47(\mathrm{~m}$, $20 \mathrm{H}), 7.31(\mathrm{~m}, 30 \mathrm{H}), 6.71(\mathrm{~s}, 5 \mathrm{H}), 5.37(\mathrm{~s}, 20 \mathrm{H}), 4.27(\mathrm{~m}, 10 \mathrm{H}), 4.18(\mathrm{~m}, 20 \mathrm{H}), 3.70(\mathrm{~m}, 10 \mathrm{H}), 3.59$ $(\mathrm{m}, 10 \mathrm{H}), 1.65(\mathrm{~m}, 10 \mathrm{H}) 1.45(\mathrm{~m}, 20 \mathrm{H}), 1.37(\mathrm{~m}, 30 \mathrm{H}), 0.88(\mathrm{~d}, 60 \mathrm{H}) ;{ }^{13} \mathrm{C} \mathrm{NMR}\left(75 \mathrm{MHz}, \mathrm{CDCl}_{3}\right)$ 
$\delta 160.87,159.12,158.63,150.12,137.17,134.52,129.91,129.10,128.90128 .67,126.22,113.27$, 97.49, 76.10, 73.88, 73.34, 67.75, 38.94, 25.12, 22.71, 22.58, 16.97. MS (MALDI-TOF) m/z, Calcd for $\mathrm{C}_{230} \mathrm{H}_{280} \mathrm{~N}_{20} \mathrm{O}_{50} 4122.0\left(\mathrm{M}^{+}\right)$, Found $4144.2\left(\mathrm{M}+\mathrm{Na}^{+}\right)$.

Macrocycle 8c: A solution of diacid chloride $7 \mathbf{b}(0.664 \mathrm{mmol})$ in methylene chloride $(2 \mathrm{~mL})$ was added dropwise to a solution of dihydrazide $6 \mathbf{c}(0.664 \mathrm{mmol})$ in methylene chloride $(30 \mathrm{~mL})$ at $0^{\circ} \mathrm{C}$ for one hour in the presence of pyridine $(3.3 \mathrm{mmol})$ and 4-dimethylaminopyridine $(0.27 \mathrm{mmol})$. The reaction mixture was allowed to warm to room temperature, and was then heated under reflux for 18 hours at which point methanol $(50 \mathrm{~mL})$ was added. Solvent was removed from the reaction mixture under vacuum and the crude product was re-dissolved in methylene chloride. $\mathrm{The}^{\mathrm{C}} \mathrm{H}_{2} \mathrm{Cl}_{2}$ solution was washed with $10 \% \mathrm{HCl}$ and brine. The organic layer was dried over sodium sulfate and concentrated to yield the crude product as a yellow solid $(0.334 \mathrm{~g}, 91 \%)$. The crude product was purified using column chromatography (silica gel in chloroform/methanol) to yield 8c $(0.229 \mathrm{~g}$, $62 \%$ ). MS (MALDI-TOF) $\mathrm{m} / \mathrm{z}$, Calcd for $\mathrm{C}_{140} \mathrm{H}_{180} \mathrm{~N}_{20} \mathrm{O}_{40} 2781.27\left(\mathrm{M}^{+}\right)$, Found $2804.5\left(\mathrm{M}+\mathrm{Na}^{+}\right)$. 


\section{NMR Spectra}

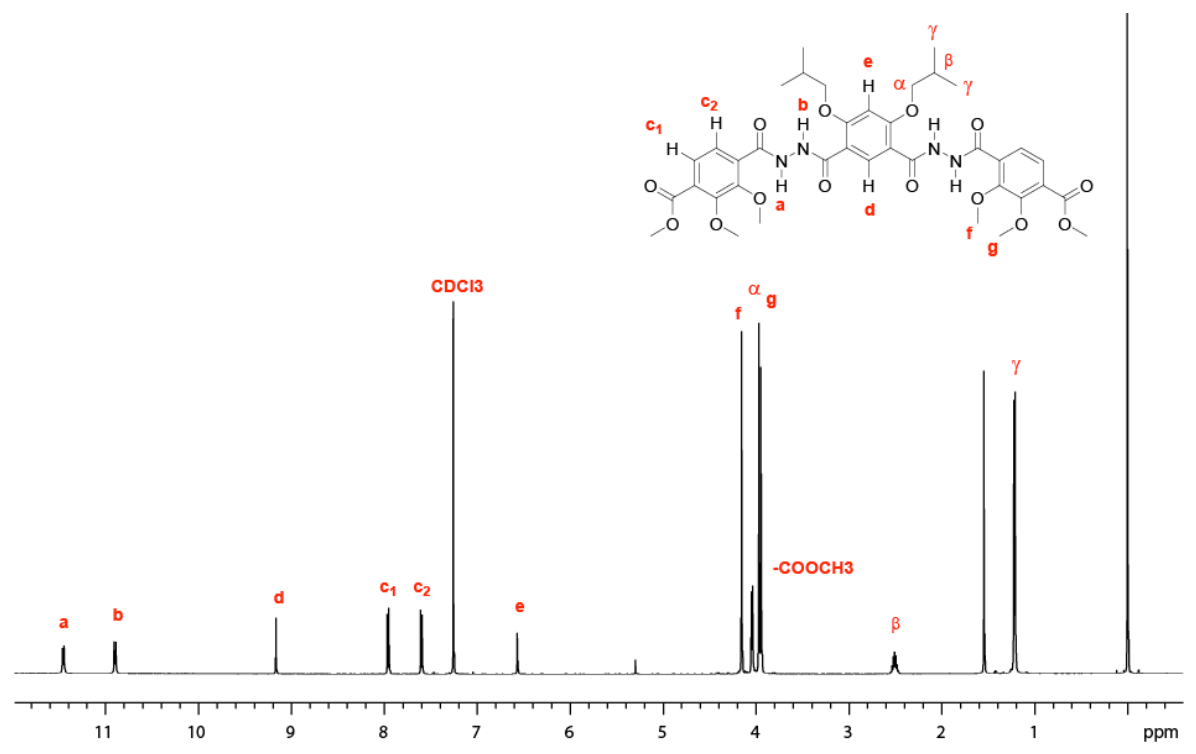

Figure S1. ${ }^{1} \mathrm{H}$ NMR spectrum of trimer $\mathbf{5 b}$ recorded in $\mathrm{CDCl}_{3}(500 \mathrm{MHz})$

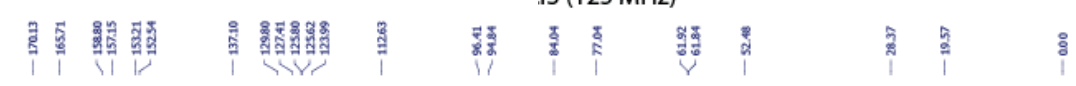

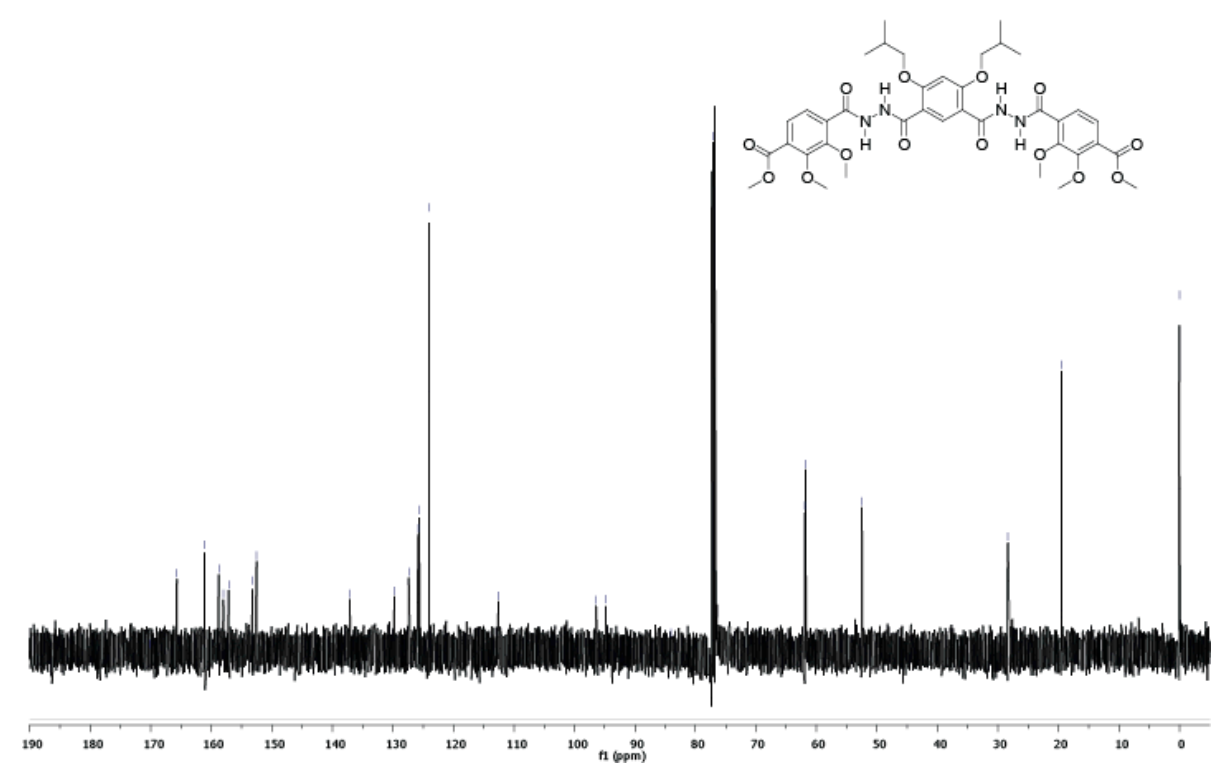

Figure S2. ${ }^{1} \mathrm{H}$ NMR spectrum of trimer $\mathbf{5 b}$ recorded in $\mathrm{CDCl}_{3}(500 \mathrm{MHz})$ 


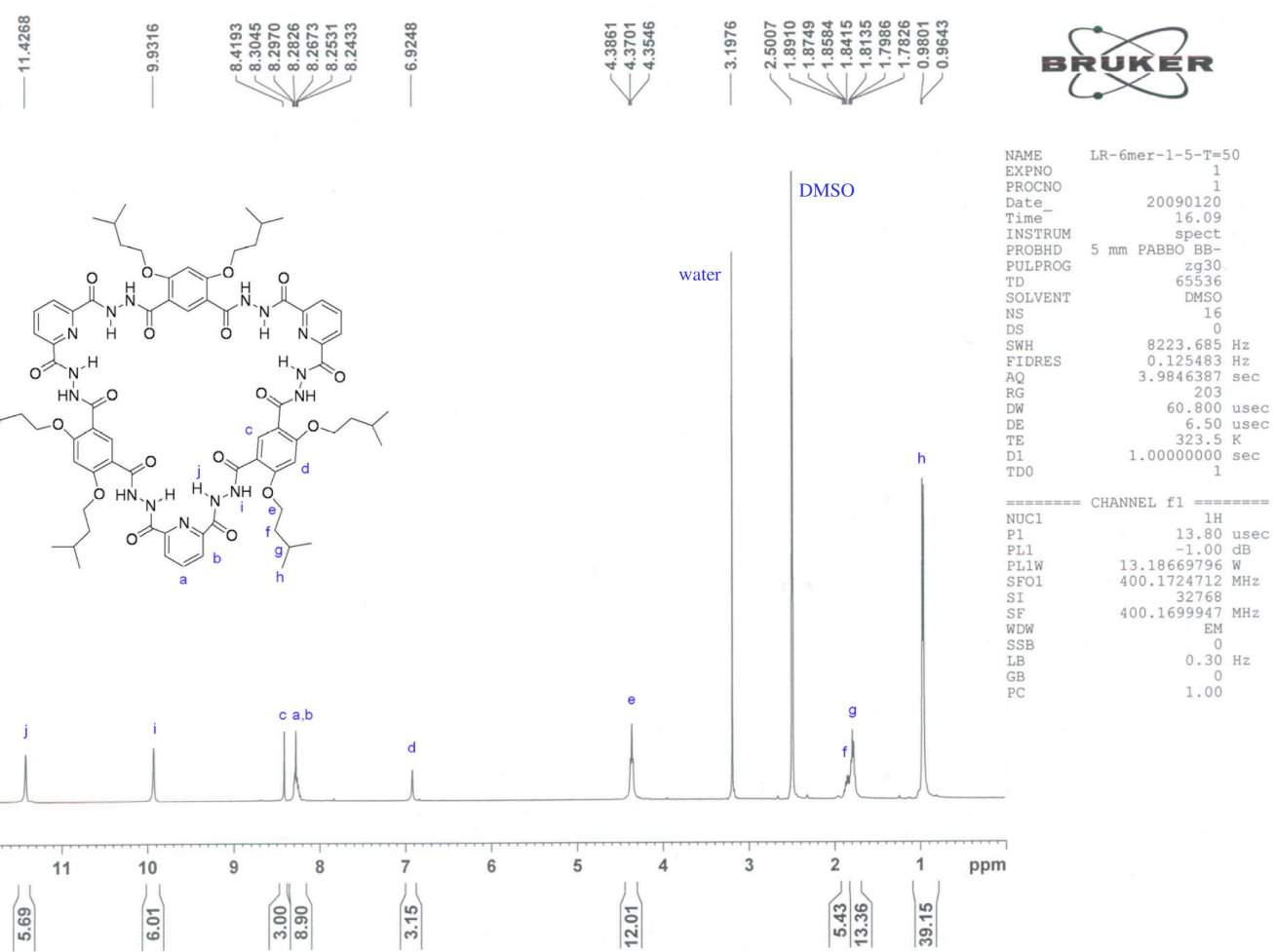

Figure S3. The ${ }^{1} \mathrm{H}$ NMR spectrum of macrocycle 4 (DMSO- $d_{6}, 400 \mathrm{MHz}$ ).

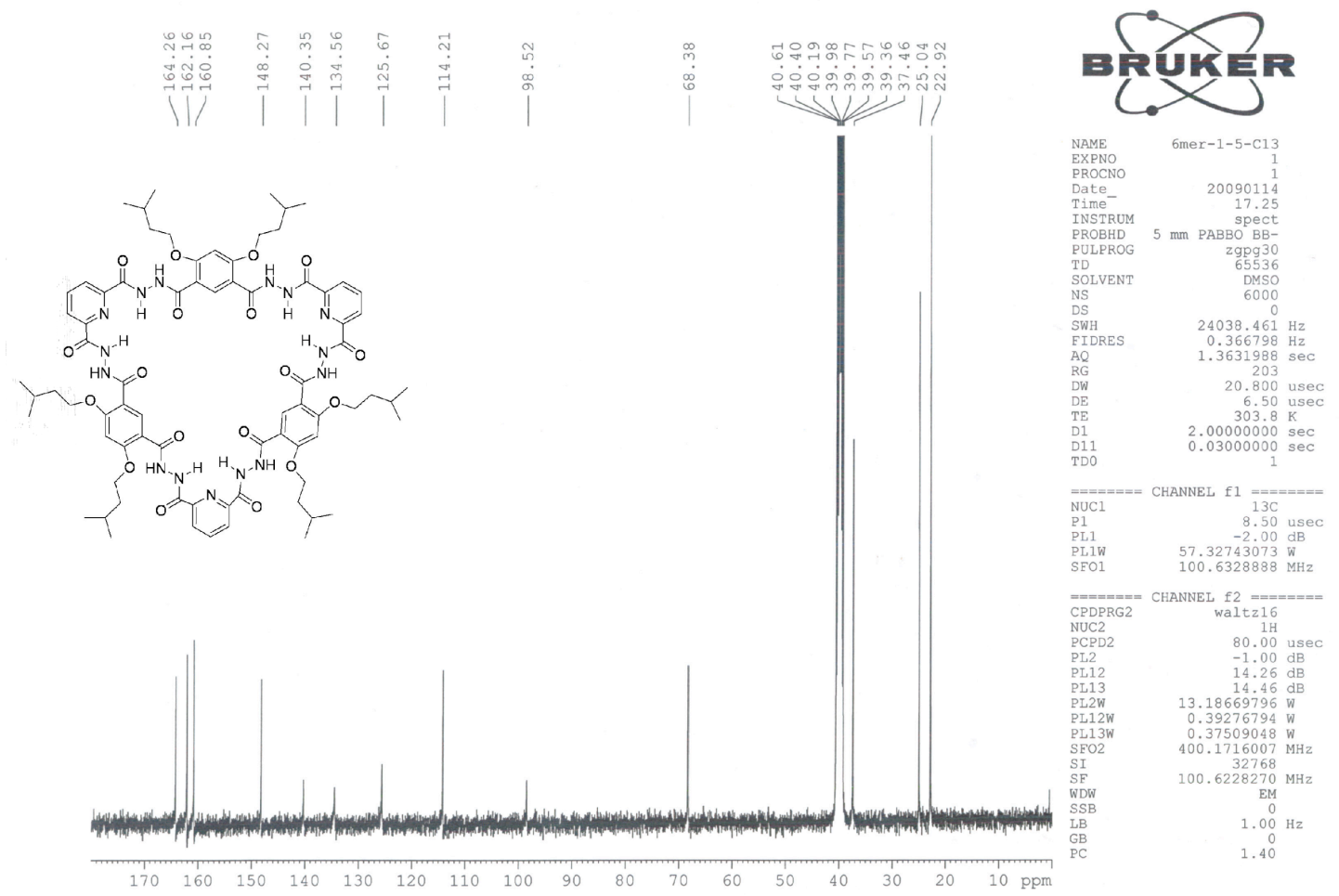

Figure S4. The ${ }^{13} \mathrm{C}$ NMR spectrum of macrocycle 4 (DMSO- $d_{6}, 100 \mathrm{MHz}$ ). 


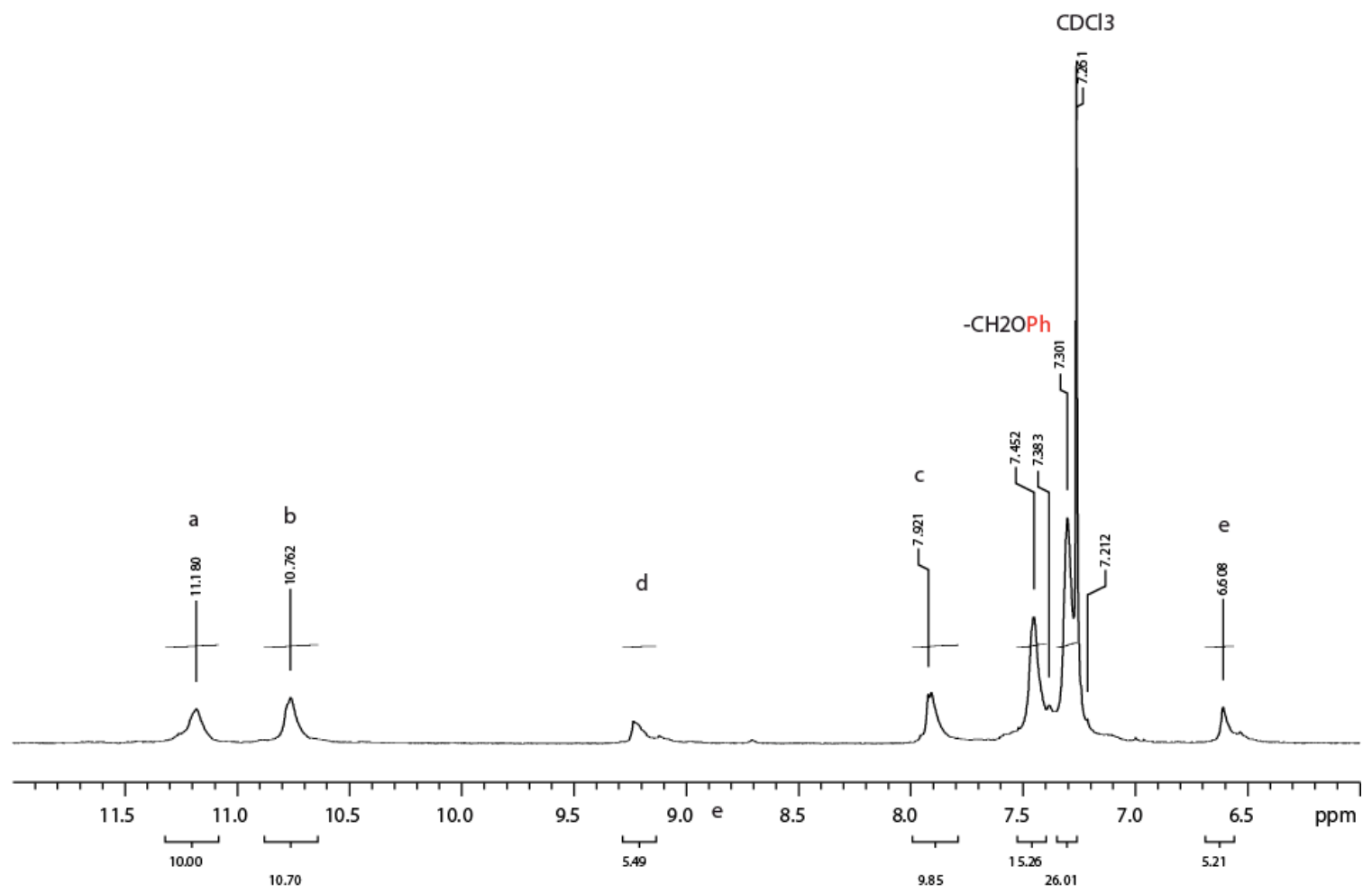

Figure S5. The ${ }^{1} \mathrm{H} \mathrm{NMR}$ spectrum of macrocycle $\mathbf{8 a}\left(\mathrm{CDCl}_{3}, 500 \mathrm{MHz}\right)$.

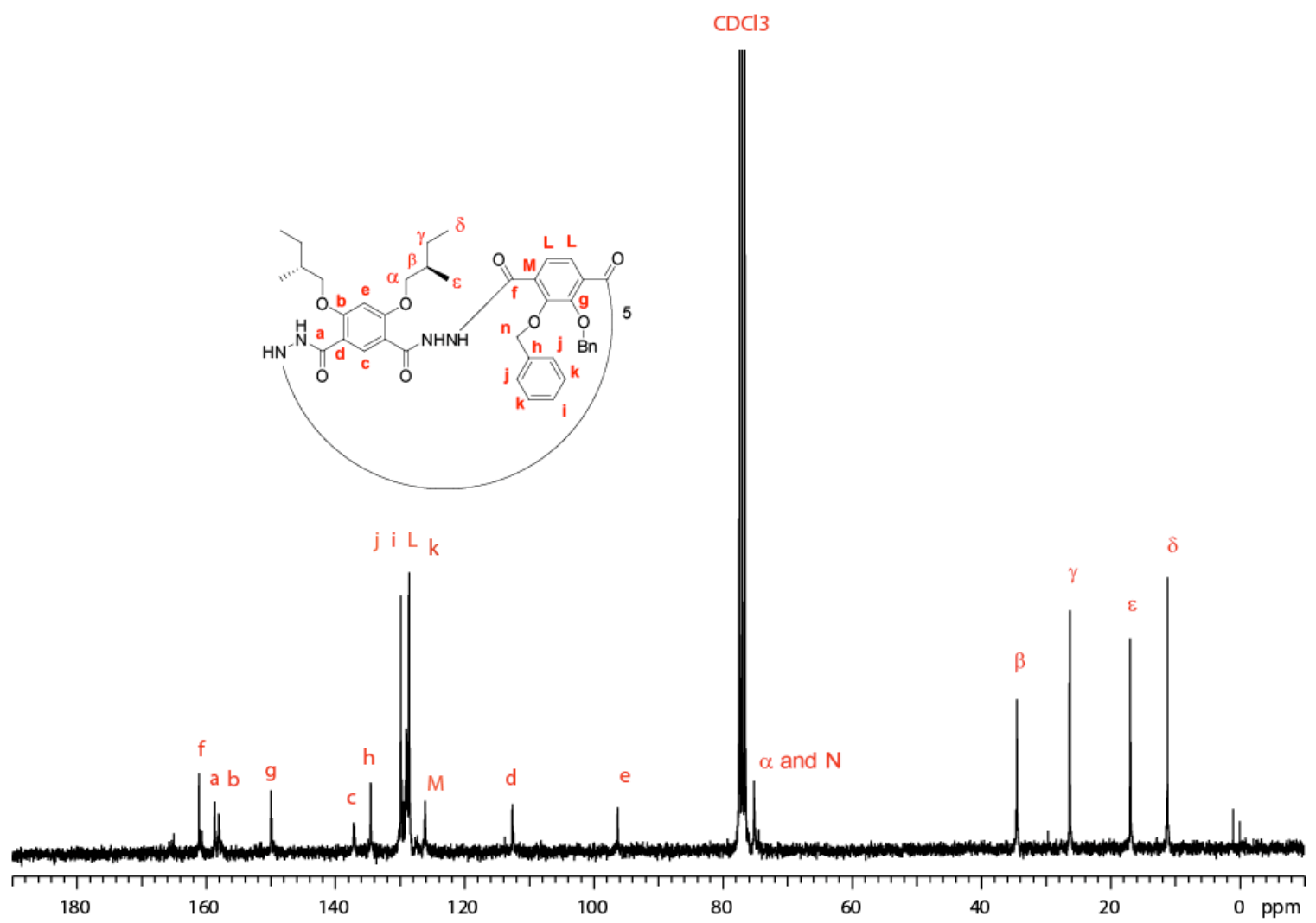

Figure S6. The ${ }^{13} \mathrm{C}$ NMR spectrum of macrocycle $8 \mathbf{a}\left(\mathrm{CDCl}_{3}, 75 \mathrm{MHz}\right)$. 


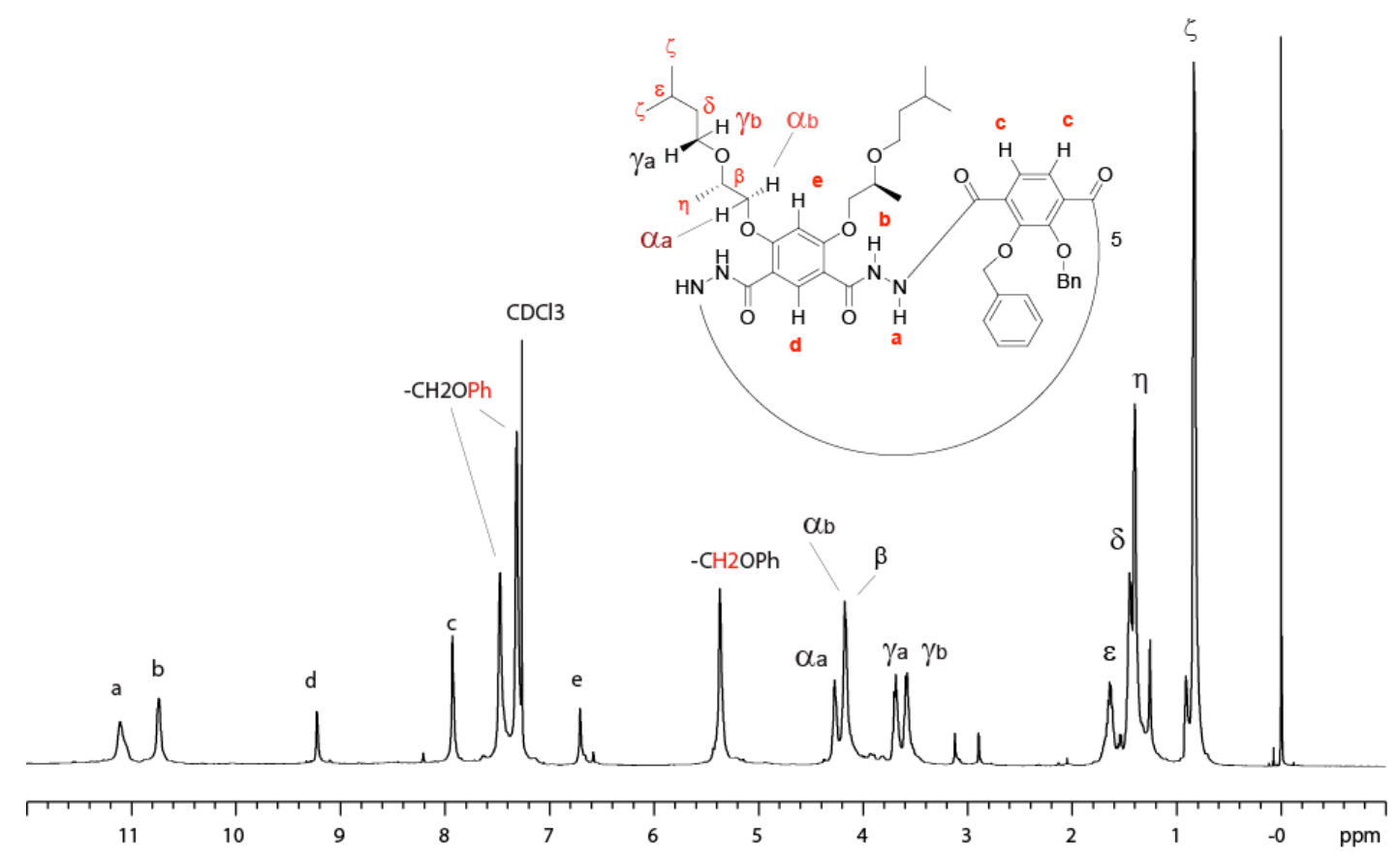

Figure s7. ${ }^{1} \mathrm{H} \mathrm{NMR}$ spectrum of macrocycle $\mathbf{8 b}\left(\mathrm{CDCl}_{3}, 500 \mathrm{MHz}\right)$.

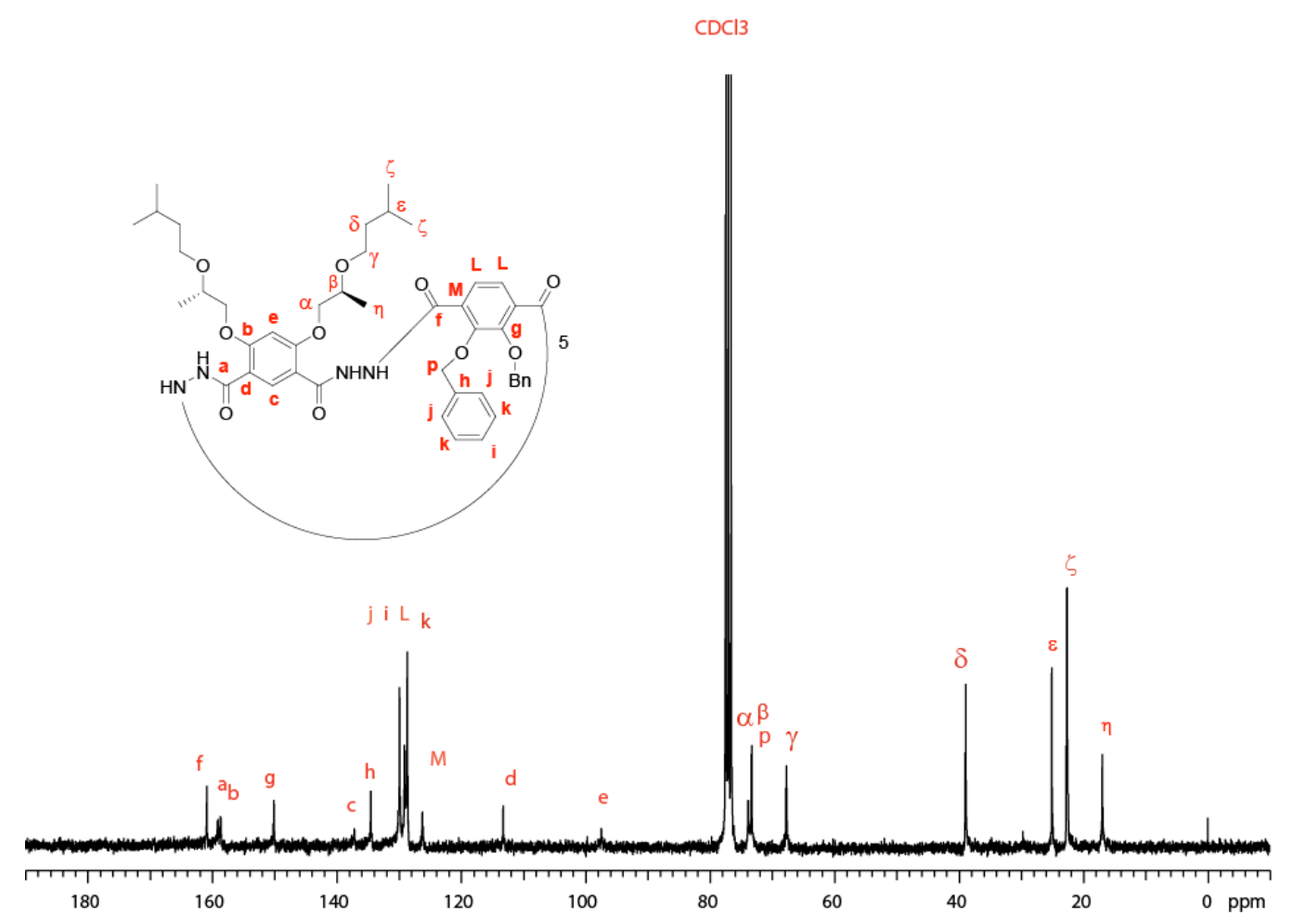

Figure S8. The ${ }^{13} \mathrm{C}$ NMR spectrum of macrocycle $\mathbf{8 b}\left(\mathrm{CDCl}_{3}, 75 \mathrm{MHz}\right)$. 


\section{MALDI Spectra}

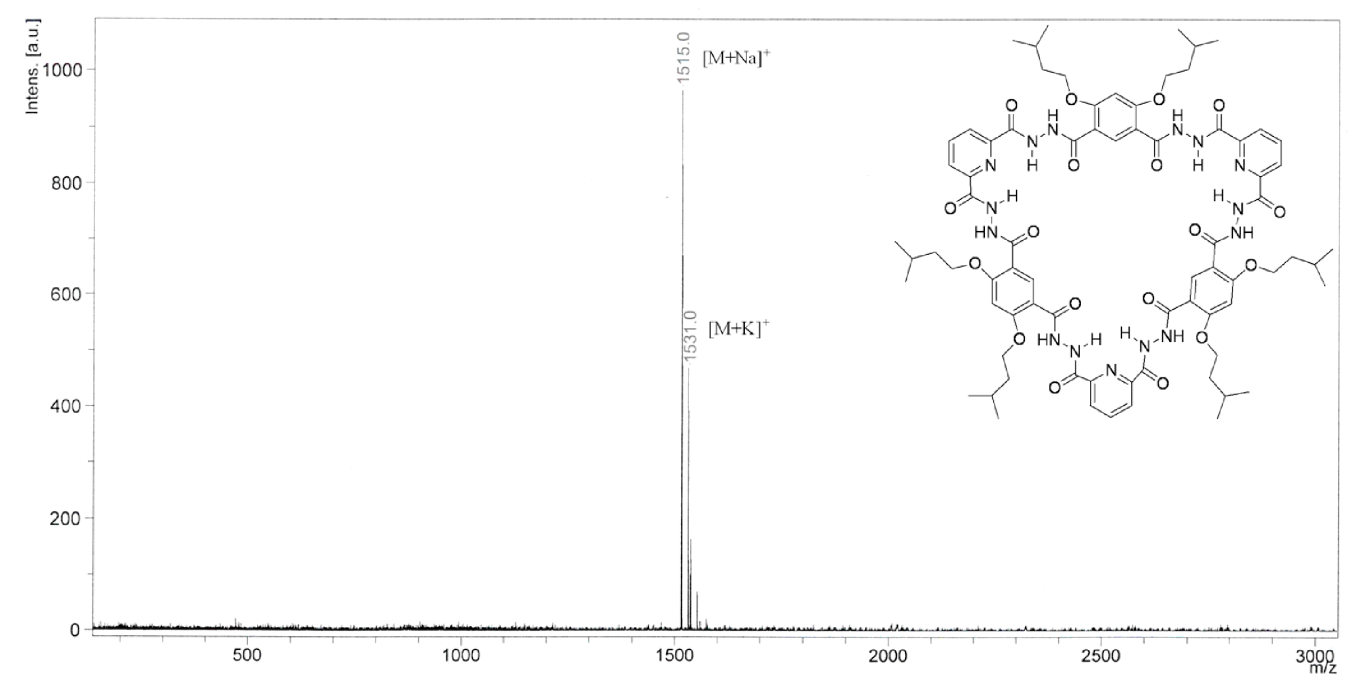

Figure S9. The MALDI spectrum of macrocycle 4.

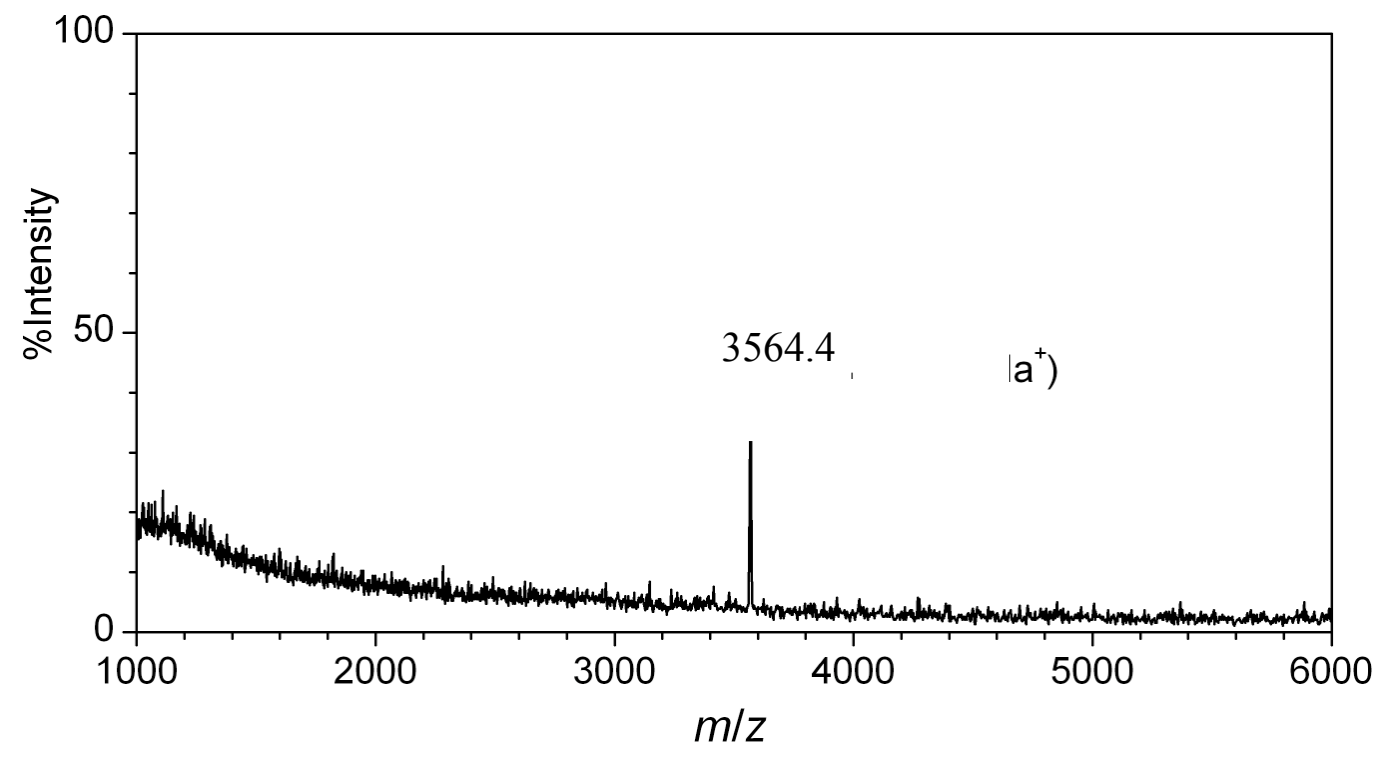

Figure S10. The MALDI spectrum of macrocycle 8a. 


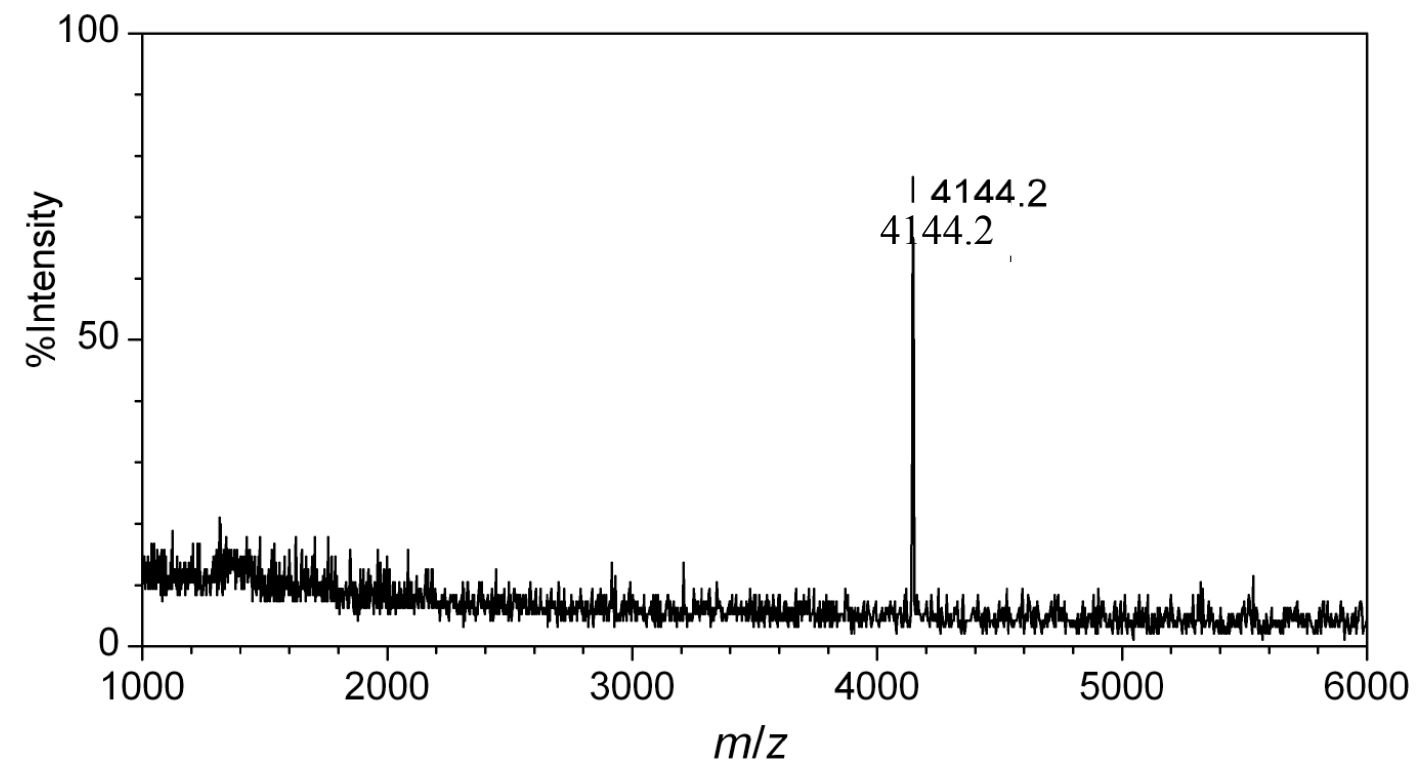

Figure S11. The MALDI spectrum of macrocycle $\mathbf{8 b}$.

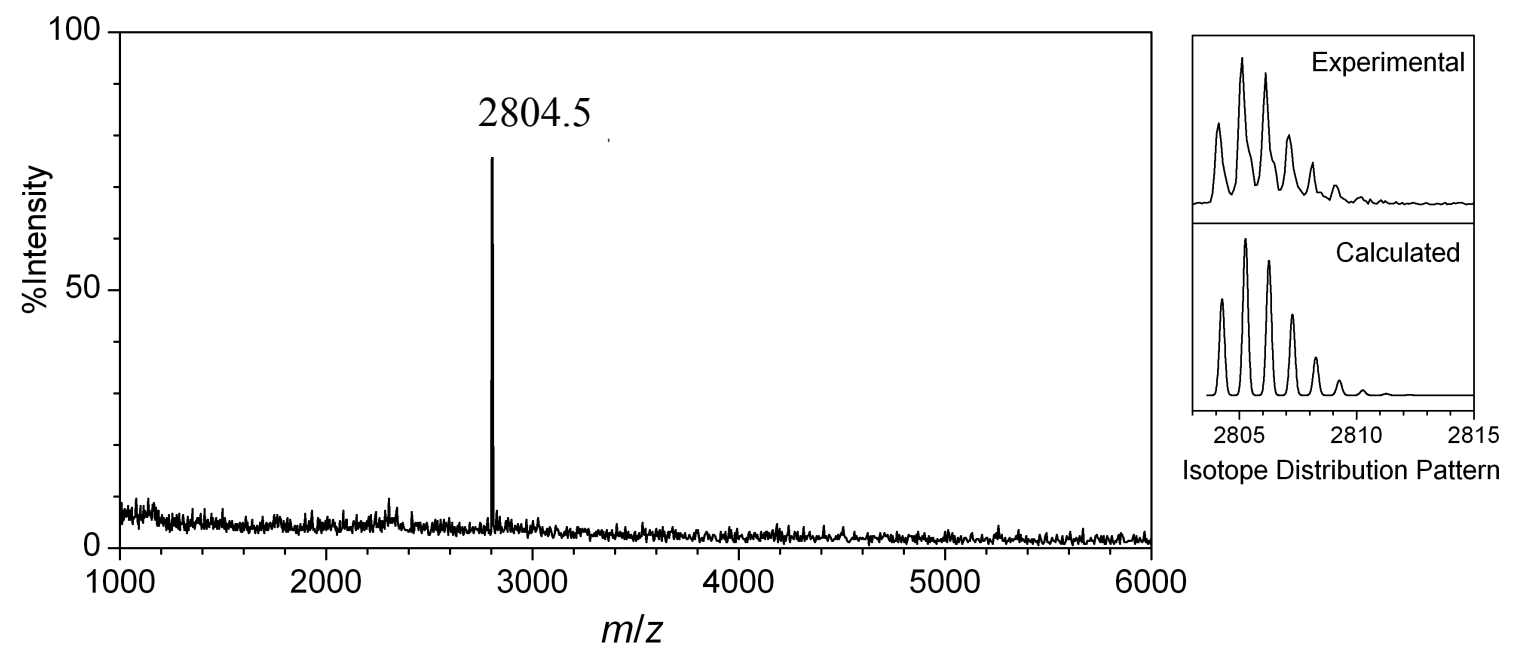

Figure S12. The MALDI spectrum of macrocycle 8c. The isotope distribution patterns of the $\left(\mathrm{M}+\mathrm{Na}^{+}\right)$ion from MALDI-TOF (top) and computer simulation (bottom) are also shown. 


\section{Ab Initio Calculation}

The ab initio density-functional calculation was carried out using the Gaussian 03 package. ${ }^{1}$ The strctures of compound 5b, macrocycles 4 and $\mathbf{8}$ were optimized by using the B3LYP/6-31G(d) level of theory and basis set. Density-functional calculation shows that all three structures are planar.

\section{Reference 1:}

Gaussian 03, Revision C.02, Frisch, M. J.; Trucks, G. W.; Schlegel, H. B.; Scuseria, G. E.; Robb, M. A.; Cheeseman, J. R.; Montgomery, Jr., J. A.; Vreven, T.; Kudin, K. N.; Burant, J. C.; Millam, J. M.; Iyengar, S. S.; Tomasi, J.; Barone, V.; Mennucci, B.; Cossi, M.; Scalmani, G.; Rega, N.; Petersson, G. A.; Nakatsuji, H.; Hada, M.; Ehara, M.; Toyota, K.; Fukuda, R.; Hasegawa, J.; Ishida, M.; Nakajima, T.; Honda, Y.; Kitao, O.; Nakai, H.; Klene, M.; Li, X.; Knox, J. E.; Hratchian, H. P.; Cross, J. B.; Bakken, V.; Adamo, C.; Jaramillo, J.; Gomperts, R.; Stratmann, R. E.; Yazyev, O.; Austin, A. J.; Cammi, R.; Pomelli, C.; Ochterski, J. W.; Ayala, P. Y.; Morokuma, K.; Voth, G. A.; Salvador, P.; Dannenberg, J. J.; Zakrzewski, V. G.; Dapprich, S.; Daniels, A. D.; Strain, M. C.; Farkas, O.; Malick, D. K.; Rabuck, A. D.; Raghavachari, K.; Foresman, J. B.; Ortiz, J. V.; Cui, Q.; Baboul, A. G.; Clifford, S.; Cioslowski, J.; Stefanov, B. B.; Liu, G.; Liashenko, A.; Piskorz, P.; Komaromi, I.; Martin, R. L.; Fox, D. J.; Keith, T.; Al-Laham, M. A.; Peng, C. Y.; Nanayakkara, A.; Challacombe, M.; Gill, P. M. W.; Johnson, B.; Chen, W.; Wong, M. W.; Gonzalez, C.; and Pople, J. A.; Gaussian, Inc., Wallingford CT, 2004.
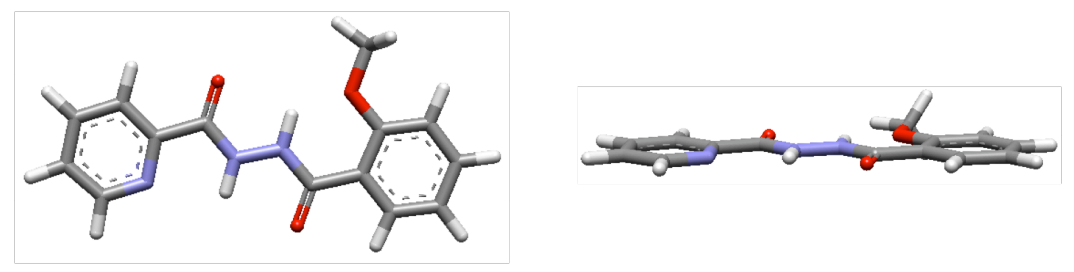

Figure S13. The top and side views of the structure of compound 1a optimized at the B3LYP/631(g)d level.
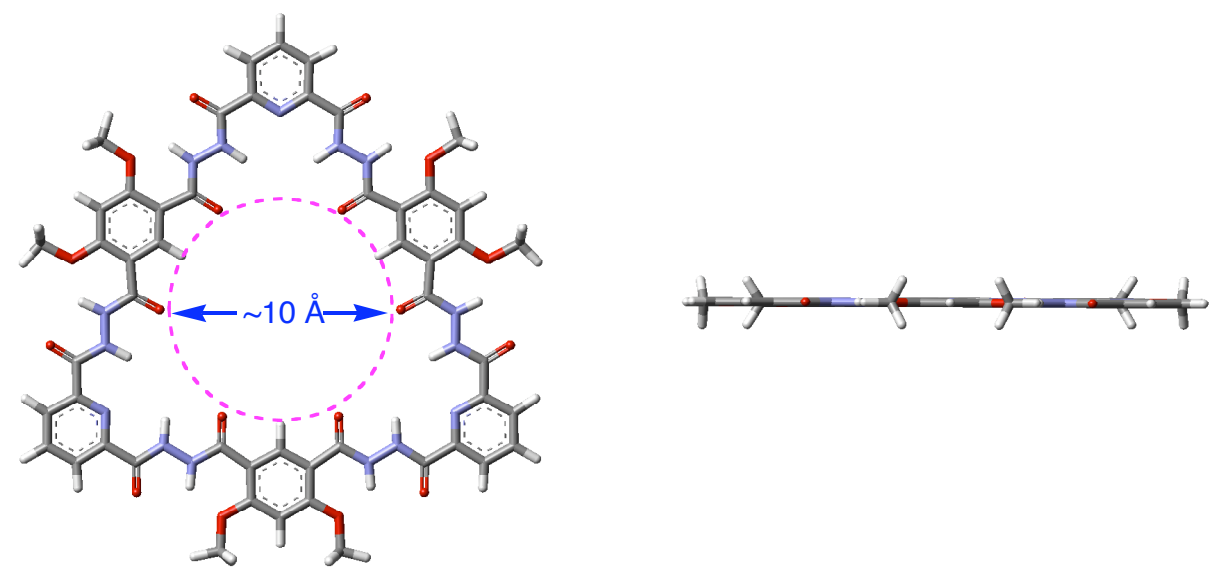

Figure S14. The top and side views of the structure of macrocycle $4\left(\mathrm{R}=\mathrm{CH}_{3}\right)$ optimized at the B3LYP/6-31(g)d level. 

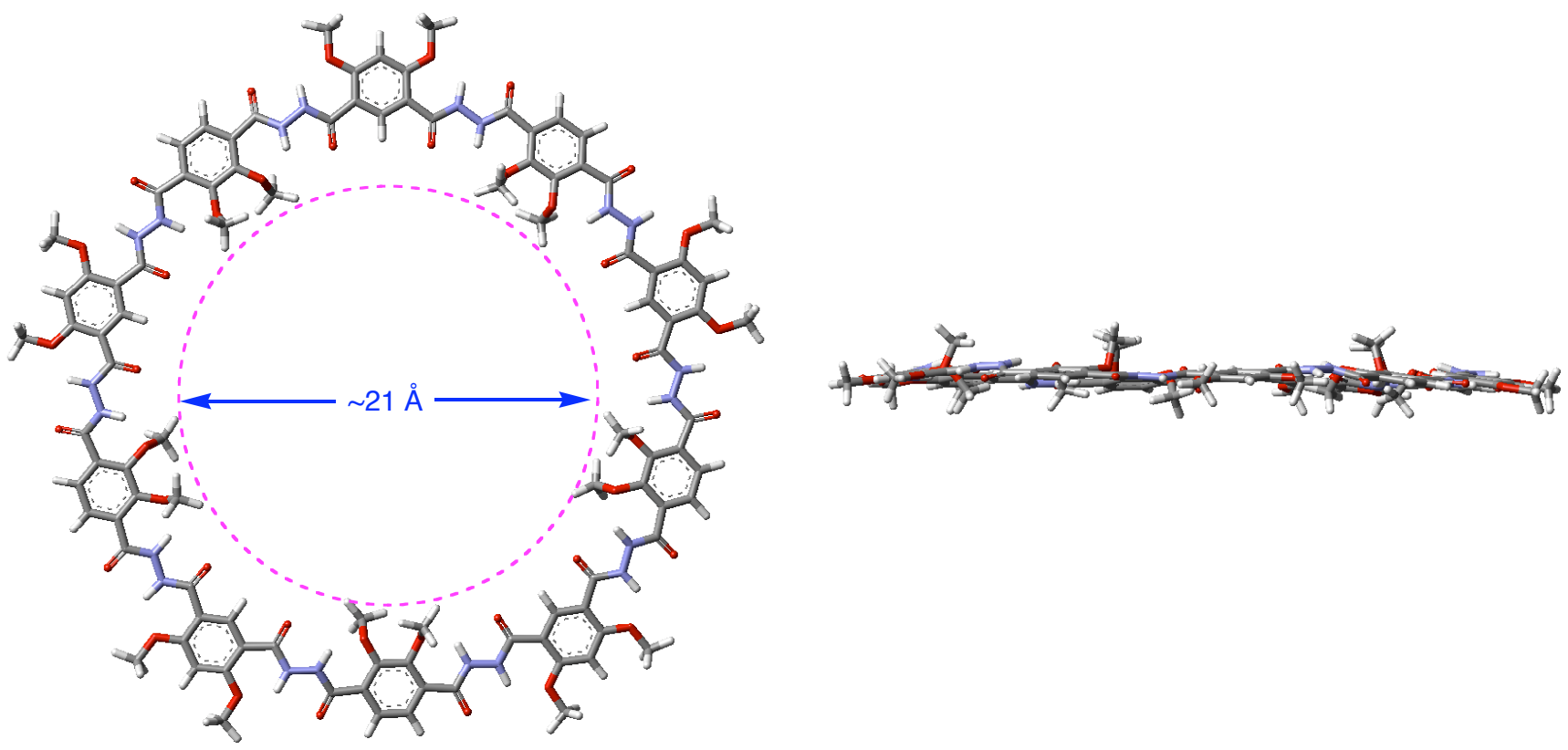

Figure S15. The top and side views of the structure of macrocycle $\mathbf{8}\left(\mathrm{R}^{1}=\mathrm{R}^{2}=\mathrm{CH}_{3}\right)$ optimized at the B3LYP/6-31(g)d level. 